\title{
Geografía del poder y diseño del espacio público periférico en el Gran Concepción
}

Geography of power and the design of peripheral public spaces in the Greater Concepción area

Rodrigo Ulloa Tesser

Arquitecto, U. de Chile. Magister en Urbanismo, U. de Chile

\section{Filiación}

Ilustre Municipalidad de San Pedro de la Paz

\section{Resumen}

El artículo busca identificar los factores jurídico-urbanos que condicionan la morfología y gobernanza del espacio público en la periferia del Gran Concepción colocando énfasis en el conocimiento de las estructuras de poder existentes en el área de estudio. Se postula que la geografía del poder privado y público limita la soberanía de las comunidades locales sobre sus espacios públicos dificultando la toma de decisiones y su diseño. Este análisis permite caracterizar la crisis del espacio público periférico, la que se expresa en dificultades en la gestión de riesgos de desastres, conectividad centro periferia, falta de identidad urbana y de barrio y gobernabilidad. A juicio del autor, las soluciones de fondo a esta crisis, pasan por cambios profundos en la institucionalidad urbana, que corrijan las inequidades de poder en las periferias de las grandes ciudades y en especial del área de estudio.

\section{Palabras Claves}

Gobernanza urbana, periferia urbana, espacio público, diseño urbano.

\begin{abstract}
The goal of this article is to identify the legal and urban factors that influence the morphology and governance of public spaces of the Greater Concepción's peripheral neighbourhoods, in order to unveil the "structures of power" acting on the area.

The main premise of the research is that the geography of power, both public and private, restricts the local communities' attributes to control and design their own spaces. This analysis, by exposing the difficulties in the management of risk zones, the poor connectivity conditions between central and peripheral areas, as well as the lack of urban identity and local governance, allows us to define the critical condition in which the peripheral public space of Concepción is immersed.

From the author's stand point, the only way to solve this situation is through deep institutional changes, aimed to amend the unbalance of power in the urban governance structures of Chile's largest metropolitan areas.
\end{abstract}

\section{Key Words}

Urban governance, urban periphery, public space, urban design.

\section{Sumario}

Introducción

Aproximación a la materia investigada.

Lugar y pertinencia.

El problema, la pregunta y una posible respuesta.

Objetivos. 
Marco Teórico.

¿Qué se entenderá por gobierno?

El espacio público desde el punto de vista jurídico.

Síntesis teórica.

Metodología.

Desarrollo

Caracterización del régimen político, económico y urbano.

Caracterización de las estructuras de dominio y gestión del espacio público.

Caracterización del espacio público periférico: orgánico, discontinuo y precario.

Resultados

Dificultades en la gestión de riesgos de desastres.

Dificultades de conectividad centro periferia.

Gobierno del espacio público periférico.

Perspectivas para el diseño del espacio público periférico.

Espacios públicos de gestión privada.

Espacios públicos "autogestionados".

Espacios públicos de gestión pública multisectorial.

Espacios públicos de gestión público privada.

Reflexiones finales

\section{I ntroducción}

Las áreas metropolitanas latinoamericanas han tenido en las últimas décadas patrones de crecimiento bastante similares, caracterizados por la expansión hacia las periferias (Villa y Rodríguez, 1997, United Nations, 1993 y 1991, Garza y Schteingart, 1994, Rodríguez y Yáñez, 1999, Cunha, 2000) (Fig 1), el predominio de los espacios de flujo, la "privatización" del espacio público y el desarrollo urbano disperso en densidad media con el consiguiente abandono de los centros históricos (Perez \& Salinas, 2006). Es decir, las periferias han adquirido un fuerte protagonismo porque en ellas se ha concentrado parte importante del crecimiento, ha sido el campo de experimentación de un tipo propio de diseño urbano y de espacio público y experimentado fenómenos socio espaciales particulares.

En tanto Área Metropolitana, el Gran Concepción no se aparta de la tendencia antes descrita (Salinas, 2010), y como tal este articulo buscará a exponer las características propias de su desarrollo periférico centrándose en las determinantes político institucionales para el gobierno y diseño del espacio público. Ello es relevante porque a juicio del autor, el diseñador y planificador urbanos deben tener plena conciencia de las limitantes y ámbitos en los cuales operan, y porque el ciudadano como agente esencial de la gobernabilidad democrática, debe guardar conciencia de las causas que se interponen entre ellos y el cumplimiento de sus anhelos, para poder de esa forma conducir adecuadamente su acción política en la ciudad.

Aproximación a la materia investigada. 
Desde la antigüedad, el espacio público ha sido un componente urbano primordial en el intercambio y resolución de intereses ciudadanos (Morris, 1979). La acepción contemporánea del término derivada de los paradigmas igualitarios de la Revolución Francesa hablan del espacio público "como una categoría determinante de la vida urbana" asociándose a esta "los postulados éticos de la cohesión social, inclusión democrática, libre expresión", todos los cuales entran en la jurisdicción del Estado para garantizar a través de su sistema jurídico los derechos fundamentales de libertad de expresión, asociación, reunión, etc. (Arroyo, 2011).

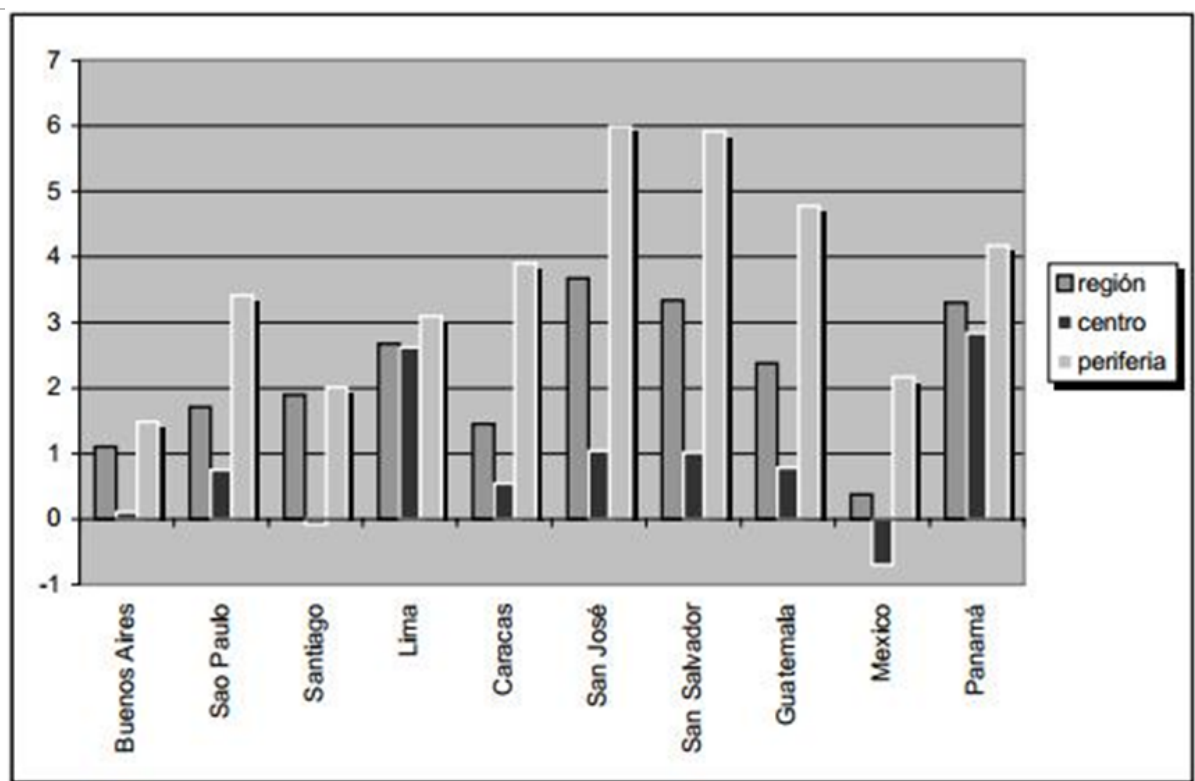

Fig 1: Tasas de crecimiento anual de áreas metropolitanas de .América Latina. División centro periferia (1990 2000). Fuente: CELADE, DEPUALC, 2000

Bajo ese paradigma, la calle es el lugar de todos, donde somos libres de reunirnos y manifestarnos sin condiciones, en el que independiente de nuestra condición socio económica, cultural, racial o política; tenemos los mismo derechos. Por tanto, a la hora de analizar la ciudad, se podría establecer una relación directa entre la cantidad y calidad de los derechos ciudadanos, las herramientas que tiene el Estado para resguardarlos, y la cantidad y calidad de los espacio públicos que existen en la ciudad en que se habita. En términos simples, el espacio público es reflejo de la democracia que se tiene y del Estado que tenemos para cautelarla.

\section{Lugar y pertinencia.}

El Área Metropolitana de Concepción se ubica al noroeste de la Región del Bio Bio, en la zona centro sur de Chile $\left(36^{\circ} 35^{\prime}\right.$ y $37^{\circ} 00^{\prime}$ de latitud sur y los $72^{\circ} 45^{\prime}$ y $73^{\circ} 15^{\prime}$ de longitud oeste) (Fig 2). El AMC abarca desde Talcahuano por el poniente a Hualqui y Santa Juana por el oriente; Lota por el sur hasta Dichato por el norte. (Ministerio de Vivienda y Urbanismo, 2003). Con mayor o menor jerarquía o importancia histórica, estos sub centros surgieron con cierta autonomía funcional e identidad cultural, y a partir de 1950 se asistió progresivamente a un proceso de conurbación sobre la base de la urbanización de los espacios intersticiales (Hoffmann \& Gysling, 2010). 
Este proceso ha ocurrido en dos fases de desarrollo urbano caracterizado el primero por un fuerte estimulo gubernamental a la industrialización a objeto de constituir una base económica para el desarrollo nacional. El segundo, determinado por una mirada crítica a las políticas de industrialización sustitutiva y un estímulo a la libertad de emprendimiento, la apertura y diversificación económica nacional. En ambos casos, decisiones públicas de cobertura nacional tomadas desde fuera de la ciudad pero con un fuerte impacto local en la imagen urbana, la ocupación territorial y el espacio público (Aliste \& Almendras, 2010). El crecimiento urbano se caracterizó por su carácter fragmentario en densidad media en torno a las vías interurbanas y líneas férreas, coexistiendo en el nuevo tejido, una diversidad de funciones urbanas y no urbanas propias de una fase transicional rural - urbana. La tendencia muestra que es posible que tras esa fase de consolidación, se constituya una mancha urbana relativamente homogénea con destino principalmente residencial. (Salinas, 2010)
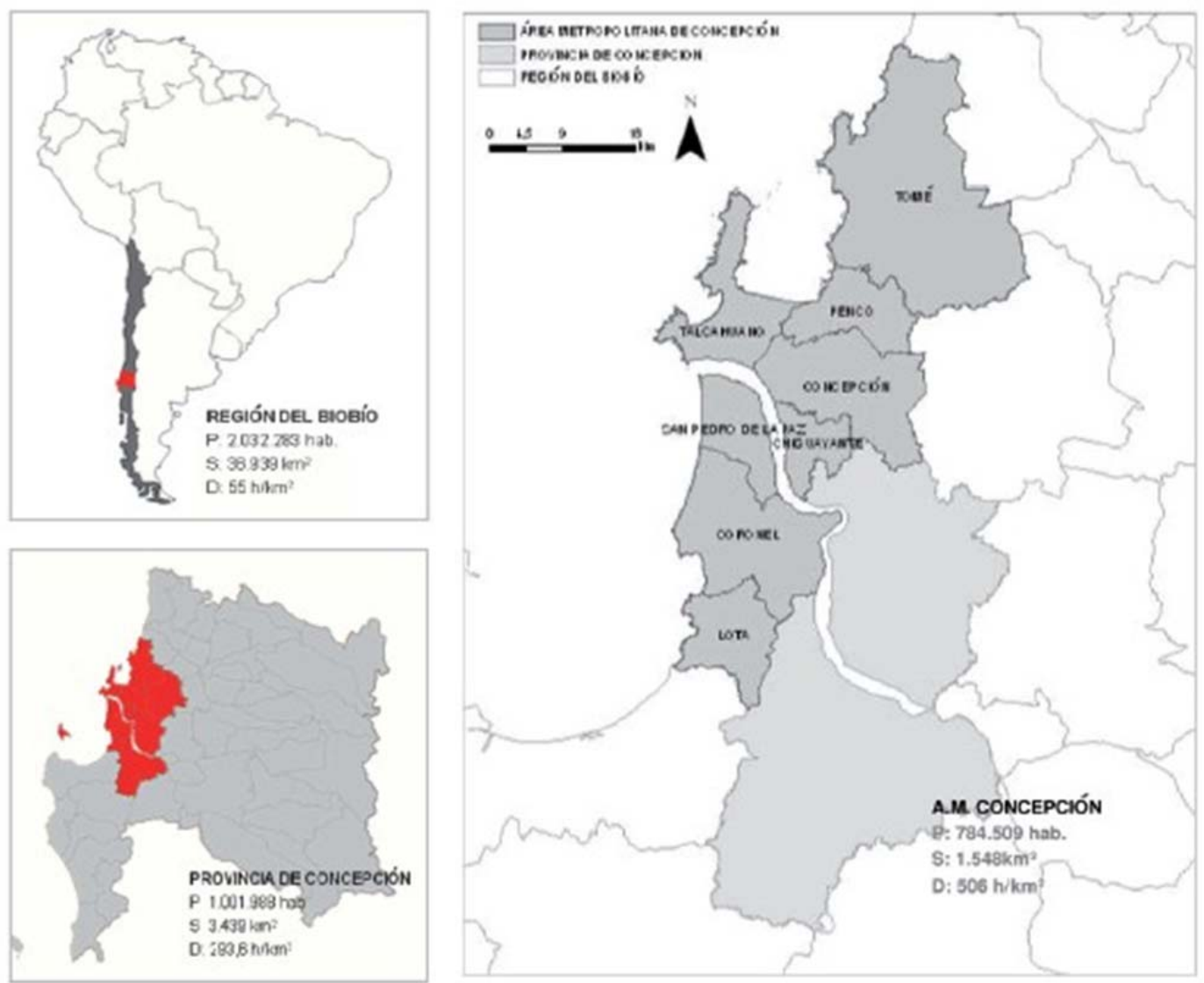

Fig 2: Área metropolitana de Concepción. Fuente: Pérez y Salinas, 2010

Llamaremos "periferias" entonces a un anillo urbano intermedio entre el centro metropolitano y las ciudades externas de la conurbación. Estaría conformado por las áreas entre, San Pedro de la Paz y Coronel, Concepción y Talcahuano, Concepción y Penco, y Concepción y Chiguayante. (Fig 3). Corresponde a un conjunto de "periferias" con determinantes políticas e históricas comunes y similitudes en sus tipologías de ocupación, densificación y espacios públicos. Por último, es un área de interés dado que son tejidos urbanos en transición funcional, en los 


\section{URBANI SMO}

cuales es posible realizar aportes relevantes para la ciudad en su conjunto por medio de la intervención asertiva sobre el espacio público.

El problema, la pregunta y una posible respuesta.

En este trabajo entonces se propondrá estudiar una porción de la AMC, especial por el protagonismo que ha adquirido en su desarrollo en el último medio siglo. Es protagónica por la intensidad de su desarrollo, relativa homogeneidad de su diseño urbano, las particularidades espaciales, problemáticas de su espacio público y las dificultades que existen para su gobierno. En lo específico, el artículo explorará las relaciones entre el poder y diseño de la ciudad y se preguntará como las estructuras de poder presentes dentro de esta parte de la urbe condicionan el gobierno y diseño del espacio público. En respuesta a esta interrogante, se propone a modo de hipótesis la existencia de una crisis en el área de estudio derivada de un desequilibrio de poder que restringe las capacidades de diseño y gobierno de los municipios y la ciudadanía sobre sus espacios públicos. Estas condiciones determinarían una especial forma de gestión del espacio público, cuyas características se pretenderá delinear al final del estudio.

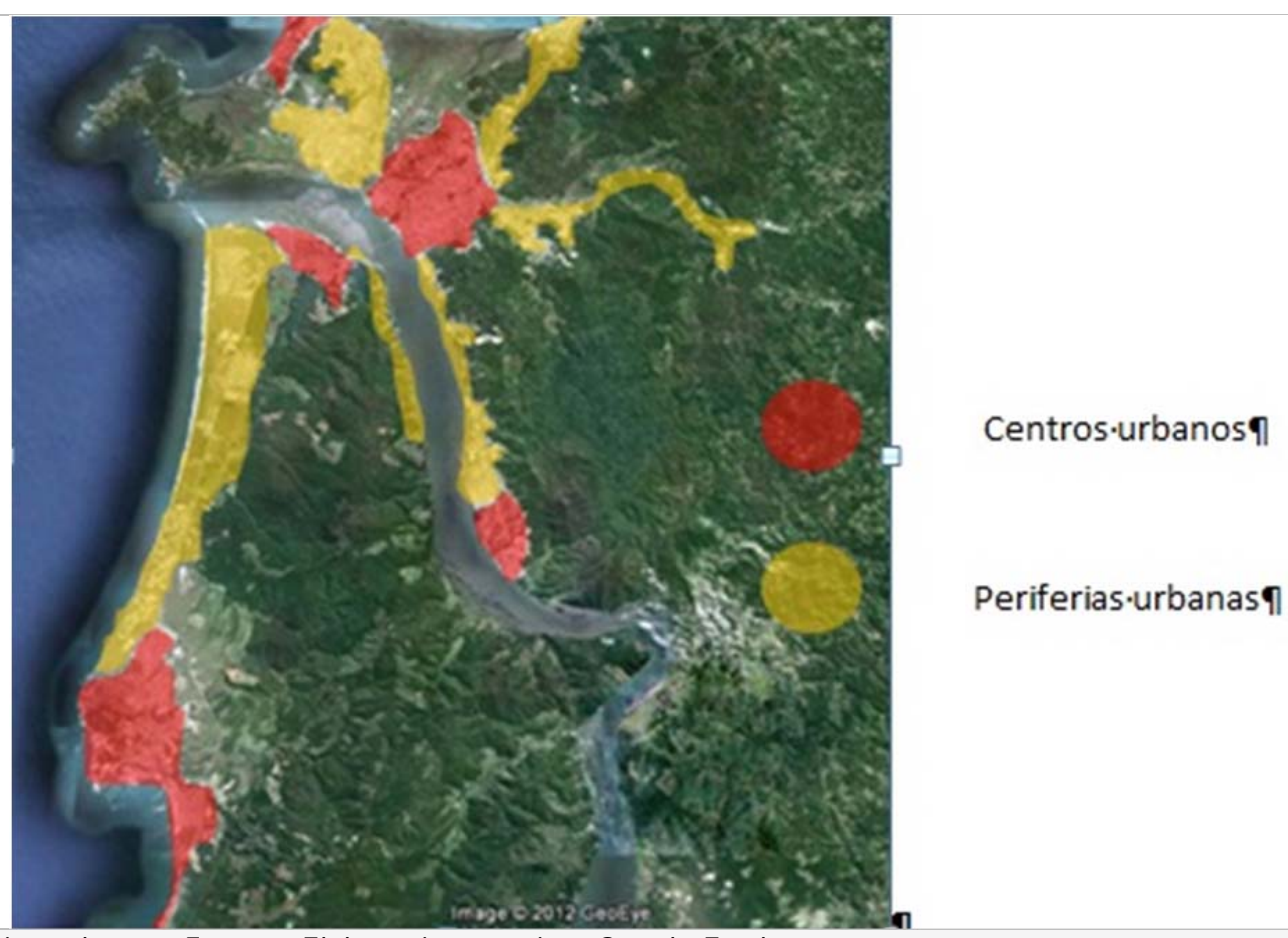

Fig 3: Periferias urbanas. Fuente: Elaboración propia y Google Earth

\section{Objetivos.}

Para dar respuesta a la pregunta antes planteada, se propondrá como objetivo principal definir la incidencia de las estructuras de poder en el espacio público periférico, en especial, su diseño y gobierno. Para ello, se estima importante caracterizar el régimen político y económico que sustenta el desarrollo urbano en Chile, así como las estructuras de dominio y administración características del área de estudio. Por último, se caracterizará el espacio público, colocando énfasis en como este es el resultado del marco político institucional y las estructuras de dominio existentes en las periferias del Gran Concepción. A modo de resumen, los objetivos son los siguientes: 
Objetivo general:

- Definir los efectos de las estructuras de poder en el diseño y gobierno del espacio público periférico.

Objetivos específicos:

- Caracterizar el régimen político y económico que sustenta el desarrollo urbano en Chile.

- Caracterizar las estructuras de dominio y gestión del espacio público presentes en del área de estudio.

- Caracterizar formal y espacialmente el espacio público periférico.

\section{Marco Teórico.}

¿Qué se entenderá por gobierno?

El término "gobierno" según la Real Academia española, refiere en tres de sus acepciones al acto de "mandar o regir algo", "dirigir un país" o "componer o arreglar", lo cual da a entender que en este acto hay un ejercicio de autoridad superior sobre un territorio, pero también una acción de mediador entre diferentes agentes que coexisten en él. Dicho en otros términos, el acto de gobernar lleva implícito con importancia equivalente, el principio de autoridad y entendimiento entre diferentes agentes de un territorio. Es por ello que para efectos de este trabajo tiene sentido descomponer el término "gobierno" en dos derivadas relevantes: "Gobernabilidad" y "Gobernancia".

"Gobernabilidad" ha sido entendido como "la manera en que se ejerce el poder en la administración de los recursos económicos y sociales para el desarrollo de un país" (Banco Mundial 1992, 3). Sin referirse al término en lo especifico, otros autores definen el antónimo (ingobernabilidad), como "una inadecuada capacidad de gobernar" (Dror, 1994) ósea, las posibilidades de acción resultantes de variables que controla el gobierno y las que no. EI PNUD la define por otro lado como la "capacidad de los gobernantes de tomar decisiones y atender las demandas en beneficio de los gobernados"

Como contrapunto, la "gobernancia" es definida como "la relación entre la sociedad civil y el Estado, entre los dirigentes y los dirigidos, el gobierno y los gobernados" (McCarney, Mohamed , \& Rodríguez, 1995) y (Wilson \& Cramer, 1996). Respecto de esta definición el PNUD precisa que la gobernanza,

“involucra mecanismos, procesos e instituciones a través de los cuales los ciudadanos y otros grupos articulan sus intereses, ejercen sus derechos legales, cumplen sus obligaciones y resuelven sus diferencias." (PNUD 1997, 2.3)

Desde ese punto de vista, esta definición involucra y permite medir la legitimidad de las decisiones que adopte la autoridad respecto de los problemas urbanos. Para Patrick le Galls, ambos términos llevan implícito la existencia de diversos actores además del gobierno municipal, incorporando una serie de organizaciones de servicio, agrupaciones ciudadanas y mecanismos para la toma de decisiones (Le Galls 1995, 60). En América y en especial el Brasil, se hizo uso de la segunda definición para referirse a la incapacidad de los líderes locales para legitimarse en sus territorios y al impedimento para implementar sus políticas públicas. (Coelho \& Diniz, 1997). Para efectos de este trabajo, haremos uso de la palabra gobierno como síntesis de ambos conceptos en el entendido que se analizará la capacidad intrínseca de los municipios 
para tomar decisiones referidas al espacio público y por otro lado como las comunidades locales inciden en ellas.

El espacio público desde el punto de vista jurídico.

Desde el punto de vista jurídico, la definición de espacio público es muy precisa: Es el bien nacional de uso público (Ministerio de Vivienda y Urbanismo, 1992). La precisión que hace el Código Civil aporta más riqueza a la definición: Según este cuerpo legal en su artículo 589,

Se llaman bienes nacionales aquellos cuyo dominio pertenece a la Nación toda. Si además su uso pertenece a todos los habitantes de la nación, como el de calles, plazas, puentes y caminos, el mar adyacente y sus playas, se llaman bienes nacionales de uso público o bienes públicos.

Finalmente, el artículo 595 de este documento complementa que "todas las aguas son bienes nacionales de uso público". Con todo, cuando nos refiramos al espacio público, haremos mención no solamente a la red de caminos, calles y plazas que en tierra firme conforman la trama urbana, sino a los cuerpos de agua en general, que articulados o no a la ciudad se encuentran dentro del área de estudio referida en este artículo. Es decir, en forma implícita, esta definición incorpora al espacio público urbano el paisaje natural que resulta de sus cuerpos de agua, lo cual, a pesar de la ambigüedad de sus alcances espaciales, entrega una perspectiva más amplia para el análisis y de alguna forma permite establecer puntos de encuentro entre la definición estrictamente jurídica y aquella que resulta del imaginario ciudadano.

\section{Síntesis teórica.}

A modo de síntesis teórica, en el artículo nos referiremos al problema del diseño y gobierno del espacio público en la periferia pencopolitana, analizando los "mecanismos, procesos e instituciones" que inciden en la conformación y sustentabilidad del espacio urbano que es de dominio, uso y goce de todos los ciudadanos; sean estos parte del entorno inmediato "vivible" físicamente o del paisaje lejano marítimo, ribereño o lacustre. Esta aproximación nos permitirá identificar los procesos que posibilitan su diseño, así como los actores que dentro del área de estudio ejercen poder y favorecen o limitan la gestión de estos lugares urbanos.

\section{Metodología.}

El presente trabajo tiene por objeto servir de base para una posterior investigación. Se soporta en el conocimiento práctico del territorio adquirido por el autor en la experiencia laboral de 15 años, agregando a ello componentes metodológicos propios del ejercicio investigativo. Esta condición permite por un lado definir los ámbitos en los que se desarrollará la futura investigación, validar o desechar posibles líneas de estudio, aspectos teóricos y métodos así como reconocer las respuestas posibles a la hipótesis planteada en este artículo.

Desde ese punto de vista, el trabajo se soporta en tres ejes indagatorios:

- El estudio bibliográfico de la legislación chilena relacionada con la institucionalidad urbana,

- El análisis de la cartografía aerofotogramétrica escala 1/10000 o 1/20000 disponible para el área de estudio y 
- Trabajo de campo que permita una mejor caracterización físico - espacial de la materia estudiada.

Respecto de lo primero, si bien el conocimiento y estudio de la Ley General de Urbanismo y Construcciones es importante para comprender como se gesta la ciudad y el espacio público en área de estudio, es tanto o más relevante el conocimiento del marco constitucional para el desarrollo urbano y el análisis de la legislación orgánica que definen como se distribuyen las capacidades decisionales de los diferentes actores urbanos en la ciudad.

El análisis cartográfico, permite por otro lado la definición de la estructura del tejido urbano periférico, los patrones de distribución del espacio público y su morfología. Este método, tiene como limitación la imposibilidad de precisar sus particularidades físicas y espaciales, razón por la cual debe complementarse con trabajo de campo que permita caracterizar en términos generales los diferentes tipos de espacio público existentes en el área de estudio. Este trabajo de campo no cubrirá todo el territorio sino que las partes más significativas de este, buscando identificar patrones morfológicos a validar en una posterior fase investigativa más acabada.

Tal y como se ha reiterado, esta propuesta metodológica solo permite aproximarse a una materia de investigación, labor que de ninguna forma pretende concluirse con este trabajo. Coloca su centro de gravedad en el análisis político institucional de la ciudad chilena y su incidencia en el diseño y gobernancia del espacio público. En tal sentido es una propuesta metodológica perfectible que a la luz de los resultados, podría ser corregida en posteriores fases de investigación.

\section{Desarrollo.}

Caracterización del régimen político, económico y urbano.

Centralismo político:

El régimen político chileno se estructura en torno a un Estado unitario formado por regiones y provincias gobernadas por el poder ejecutivo y comunas administradas por municipios políticamente autónomos (Republica de Chile, 1980). En las ciudades de mayor tamaño, las comunas son unidades administrativas sub - urbanas, lo que se ratifica en el Gran Concepción. Es decir que en estos casos las ciudades son administradas por un conjunto de unidades administrativas políticamente autónomas unas de otras sin coordinación administrativa efectiva.

En los siguientes niveles, las provincias y regiones son estructuras político administrativas supra urbanas que administran escalas muy superiores al nivel urbano. Ello determina que para la resolución de los grandes problemas urbanos la acción de los municipios es insuficiente y la intervención de la autoridad regional potencialmente ineficiente. Esto aplica para los problemas de conectividad, transporte, equipamiento urbano, medioambiente, etc.; para los cuales las atribuciones y presupuestos municipales son muy limitados.

Ejemplifiquemos: La vialidad interurbana es de tuición de la Dirección de Vialidad del Ministerio de Obras Públicas (Ministerio de Obras Públicas, 1997) y las redes ferroviarias de Ferrocarriles del Estado. Ambos organismos son fuertemente centralizados en la capital nacional y su escala de trabajo es regional y subsidiariamente urbana. A nivel urbano, la vialidad es administrada en forma conjunta por los municipios y el SERVIU (Ministerio de Vivienda y Urbanismo, 1975) (Ministerio del interior, 2002), este último un organismo regionalizado pero dependiente del nivel central. Los cuerpos de agua son fiscalizados por la Dirección de Aguas del Ministerio de Obras Públicas (Ministerio de Obras Públicas, 1997) y lo mismo llevan a cabo las Gobernaciones 
Marítimas dependientes del Ministerio de Defensa en el caso de los lagos navegables y playas (Ministerio de Hacienda, 1960). Las materias vinculadas al transporte público son de responsabilidad de la Secretaría Regional Ministerial de Transporte, dependiente de la cartera ministerial del mismo nombre.

Se podría seguir profundizando en la complejidad de la administración del espacio público y como ésta se dispersa en una gran cantidad de organismos públicos desterritorializados y centralizados en la capital, pero los ejemplos señalan que dentro de la ciudad y especialmente el área de estudio, el gobierno y administración de las redes de transporte y espacio público, está dispersa en varios organismos públicos y solo una parte muy limitada está en manos de los municipios. Desde una perspectiva política, los organismos públicos como la Gobernación Marítima, SERVIU, Dirección de Vialidad o SERVIU, SEREMI de Transportes no son dependientes de los municipios, lo cual limita la soberanía ciudadana. En efecto, las autoridades que se eligen democráticamente tienen poca o ninguna injerencia en aquellos agentes públicos que tienen capacidades administrativas y financieras para resolver las problemáticas del espacio público (Ahumada, 2009).

Modelo neoliberal:

Como resultado de los cambios políticos acaecidos en Chile tras el golpe militar de 1973, este país transitó rápidamente de un modelo económico capitalista post - liberal con un Estado económicamente fuerte y "benefactor" a uno igualmente capitalista pero con una participación del Estado en la economía nacional mucho más limitada (De Mattos, 2002). Paulatinamente materias como la energía, la educación, la salud, entre otros; fueron traspasados a la gestión privada y en consonancia con ello, la participación del sector privado en el desarrollo urbano también experimentó un aumento significativo. Las claves urbanas de este modelo de desarrollo son las siguientes y fueron replicadas como tales desde el modelo capitalista europeo de los albores del siglo XIX (Benevolo, 1982).

- El propietario y el inversionista privados participan en forma mayoritaria y autónoma en el desarrollo urbano.

- El administrador urbano (Estado o Municipio), define la red viaria, las normas urbanas de uso de suelo y edificación para que el propietario e inversionista ejerzan su participación predominante en el desarrollo urbano.

- El administrador urbano interviene en el espacio público definiendo las líneas oficiales, antejardines, alturas máximas de edificación; es decir las envolventes del espacio privado, sin interferir en dentro de este último.

En el caso chileno, ciertas particularidades restringen más aún a los municipios y Estado en general en materia de planificación urbana. (Ministerio de Vivienda y Urbanismo, 1975) y (Ministerio de Vivienda y Urbanismo, 1992):

- La red de espacios públicos que definen los planes reguladores es solo un gravamen sobre la propiedad privada, no definiéndose mecanismos para implementarla.

- Dicha red, es limitada y solo puede definir las vías de mayor estándar, excluyendo las vías locales y de servicios de menor tamaño.

- Dichos gravámenes están sujetos a caducidad, es decir si no se materializan en un determinado periodo, estos desaparecen como exigencia normativa a los propietarios e inversionistas. 
- El Estado y el Municipio, no tiene mecanismos que permitan comprometer la ejecución de la red de espacios públicos necesarios para la ciudad y refrendados en el Plan Regulador Comunal.

Marco normativo para el desarrollo urbano periférico:

El desarrollo urbano se rige entonces por la iniciativa principalmente privada del propietario y el inversionista; y el municipio regula el diseño y uso del espacio público a través del Plan Regulador Comunal, Intercomunal o Metropolitano según sea el caso. Solo en el caso de los loteos, el propietario y/o inversionista deben contribuir con la ejecución de espacio público de acuerdo a sus necesidades funcionales y criterios básicos establecidos en la ley urbana. Esta obligación se extiende a los condominios y subdivisiones en los casos que los predios involucrados estén afectados por declaratorias públicas del PRC (Ministerio de Vivienda y Urbanismo, 1992).

El urbanizador debe incluir en sus loteos un determinado porcentaje de calles y áreas verdes públicas implementadas con las condiciones mínimas establecidas en la ley urbana, el PRC y la Ordenanza Municipal de Ornato (Ministerio de Vivienda y Urbanismo, 1992). Con excepción de las obligaciones generales que impone el instrumento de planificación, el urbanizador es autónomo en materia de diseño urbano y en especial en materia de distribución e implementación del espacio público en el área urbanizada, en tanto dé cumplimiento a las obligaciones reglamentarias.

Caracterización de las estructuras de dominio y gestión del espacio público.

Estructuras de propiedad: Predominio de grandes predios privados.

En mayor o menor grado, las periferias urbanas del Gran Concepción corresponden a un mosaico de urbanizaciones y grandes paños de terreno de dominio privado (Fig 4). Destacan entre ellas las empresas forestales, inmobiliarias y del retail que paulatinamente van "colocando" en el mercado sus predios, incorporándolos al tejido urbano en el momento y forma de su conveniencia. El caso de las empresas forestales es particularmente emblemático. Corresponden a enormes paños de terrenos a veces mayores que las propias manchas urbanas, sometidos a administraciones desterritorializadas y regímenes productivos y jurídicos muy ajenos a la realidad urbana. (Sassen, 2003)

En la práctica y aun cuando los planes reguladores comunales inscriban dentro de sus límites urbanos los predios forestales, sus normas tienen escasa capacidad regulatoria en ellos, con lo cual las facultades municipales y por ende la soberanía ciudadana se ve fuertemente coartada. Al ser espacios no urbanizados no tienen una red espacios públicos, lo cual contribuye a la desvinculación de estos territorios del resto de la ciudad. En el caso de San Pedro de la Paz por ejemplo, los cuerpos de agua que son espacios públicos por definición, en la práctica no logran vincularse en forma efectiva al tejido urbano, dado que están contorneados por predios forestales que coartan el acceso público y en los cuales, como habíamos dicho anteriormente, ni el Estado ni el Municipio tienen formas efectivas de intervenir (Fig 5). 


\section{URBANI SMO}

ISSN 0717-5051

http://revistas.uchile.cl/index.php/RU/index
Geografía del poder y diseño del espacio público periférico en el Gran Concepción Geography of power and the design of peripheral public spaces in the Greater Concepción area

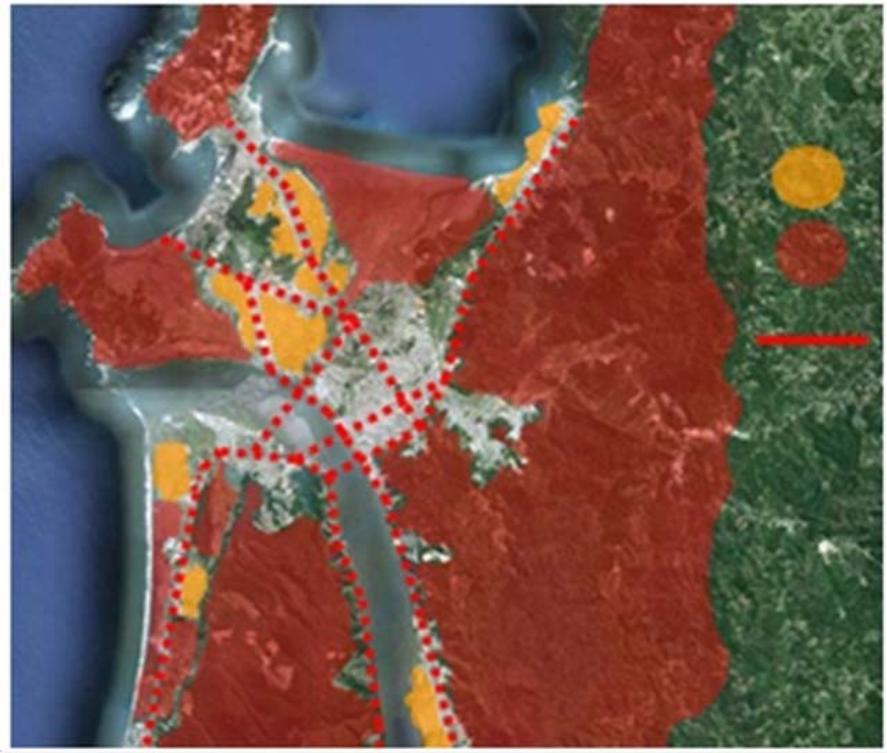

Tejido urbano

Grandes paños

Vias interurbanas

Fig 4: Estructuras de dominio. Fuente: Elaboración propia y Google Earth

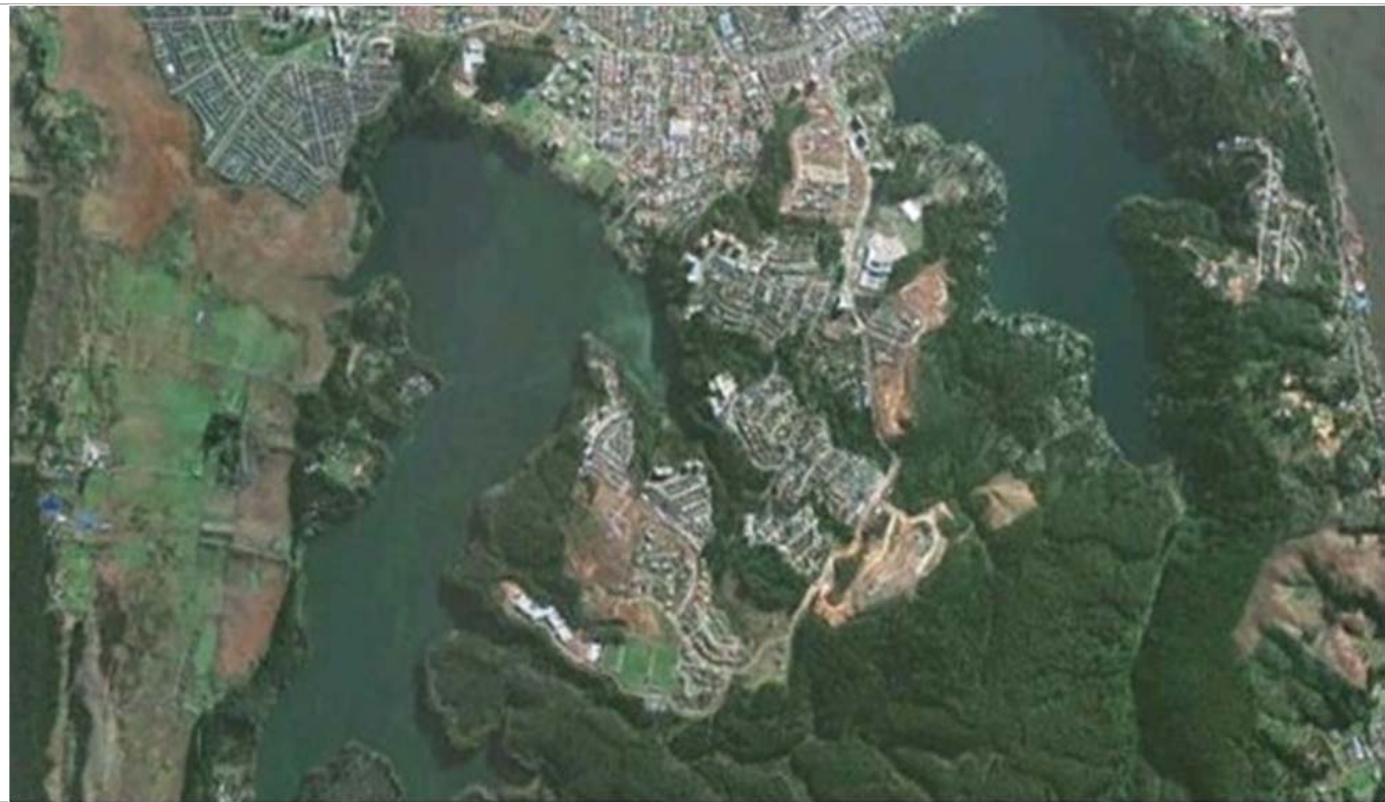

Fig 5: Tejido urbano y forestal en San Pedro de la Paz. Fuente: Elaboración propia y Google Earth

Gestión del espacio público: Predominio de poderes desterritorializados.

El diseño y administración de las vías públicas está sometida a la supervisión de SERVIU (vialidad urbana) (Ministerio de Vivienda y Urbanismo, 1975), Dirección de Vialidad (vialidad interurbana) (Ministerio de Obras Públicas, 1997) y los atraviesos sobre líneas férreas a la autorización y supervisión de Ferrocarriles del Estado. La gestión de tránsito por otro lado es materia del Ministerio de Transportes a través de la Unidad Operativa de Control de Tránsito y en menor grado de los Municipios. Por último, la intervención en los cuerpos de agua es de tuición de la Gobernación Marítima y la DGA. Solo las áreas verdes están sometidas a la 
fiscalización de la Municipalidad respectiva (Ministerio del interior, 2002). Como se detallará más adelante, el área de estudio se caracteriza por el predominio de las vías interurbanas y ferroviarias y está marcada por la presencia de cuerpos de lacustres y borde costero dentro o tangente al tejido urbano. De ello resulta que en el área de estudio, el peso específico de los organismos públicos no locales afecta considerablemente la gestión soberana del espacio público.

Una vez recibidas las obras de urbanización, los espacios públicos locales son administrados por el Municipio. Bajo esa condición, este es el receptáculo de las demandas ciudadanas sobre el espacio público, especialmente en las periferias urbanas donde se concentran los grupos de menor nivel socioeconómico. A falta de recursos del erario municipal, los municipios tienen acceso a diversas líneas de financiamiento público externas para el diseño del espacio público. Disponen de mecanismos de resolución anual y monto limitado y otras líneas de financiamiento más lentas, sometidos a la evaluación del Ministerio de Desarrollo Social para proyectos de mayor costo. Los primeros, más ejecutivos, solo son viables para obras de menor envergadura. Los segundos, permiten intervenciones más radicales sobre el espacio público, pero en el cual también intervienen actores públicos centralizados como el MDS, MOP y MINVU. Conspira entonces en contra de las capacidades locales para diseñar e intervenir en los espacios públicos, los limitados presupuestos municipales y la lentitud para acceder a recursos mayores de definición centralizada.

Como mencionábamos al comienzo del trabajo, el área de estudio corresponde a territorios intersticiales entre centros urbanos originalmente autónomos. Antes del proceso de conurbación de las décadas de 1960, 1970, 1980, 1990 y 2000; estos centros urbanos eran conectados por uno o pocos caminos públicos o redes ferroviarias con poco "roce" en su trayecto debido a su función interurbana y el destino principalmente forestal de los predios que los circundaban. El limitado compromiso de inversión pública durante las últimas tres décadas en relación al intenso desarrollo periférico en igual periodo, determinó la dependencia de la periferia urbana de estas vías estructurantes interurbanas sub dimensionadas para los nuevos requerimientos. Dichos espacios públicos de flujo, de administración total o parcialmente desterritorializada (MOP - FFCC), limitan y la administración por parte de los municipios de sus espacios públicos y consecuencialmente, la soberanía ciudadana sobre estos.

El modelo de financiamiento de espacios públicos por medio de la concesión a privados acentua dicho efecto (Ministerio de Vivienda y Urbanismo, 2003). Si bien permite el ingreso de capitales a la ciudad, no es menos cierto que entrega al inversionista el control sobre la administración del espacio público y con ello el control del acceso y usos de estos espacios, afectando la soberanía ciudadana y municipal sobre los espacios públicos concesionados. En el caso de las autopistas concesionadas, el diseño urbano radica en el Departamento de Concesiones del Ministerio de Obras Públicas que dada su estructura administrativa, se encuentra en la capital.

\section{Caracterización del espacio público periférico: orgánico, discontinuo y precario.}

La morfología de la ciudad periférica liberal, postliberal y contemporánea ya ha sido descrita por varios autores (Benevolo, 1982). La tendencia de esta es a la densificación del centro y la dispersión en baja densidad de la periferia (De Mattos, 2002). Esta dispersión no es homogénea, sino en base a concentraciones urbanas aisladas del tipo "salto de rana" (Fig 6), dejando entre medio espacios sin urbanizar con usos por lo general no urbanos. El caso del área de estudio, no es muy diferente (Hoffmann \& Gysling, 2010). Durante los últimos 60 años el desarrollo periférico del Gran Concepción ha ocurrido en torno a sus cuatro ejes en base a 
asentamientos principalmente residenciales aislados, copando paulatinamente los espacios intersticiales que van quedando entre ellos (Salinas, 2010).

Considerando el contexto político institucional mencionado anteriormente, esto es, la autonomía de acción del propietario y el inversionista; el espacio público se desarrolla en forma discontinua y "orgánica". Discontinua porque el espacio público solo se materializa en la medida que el propietario y el inversionista urbanizan y "orgánica", porque la precariedad de la red viaria propuesta por los planes reguladores comunales, motiva que las tramas urbanas se desarrollen al arbitrio principalmente del propietario e inversionista privados.( Imagen 7: Trama discontinua y orgánica (Concepción). Fuente: Elaboración propia y Google Earth). Consecuencialmente, la red de espacios públicos periféricos tiene una expresión alveolar compuesta por una estructura primaria de vías troncales y expresas, tramas urbanas segundarias de vías locales, servicio y colectoras, y pasajes (Fig 8). Estos últimos, mayoritarios en las tramas urbanas, suelen tener anchos entre 6 y 8 metros sin aceras, mientras las calles tienen anchos de 6 a 7 metros con aceras de $80 \mathrm{~cm}$. El criterio de diseño enfocando a la racionalización del suelo y la optimización de los recursos de inversión, determina tramas reticulares con un acceso a la vía primaria intercomunal.

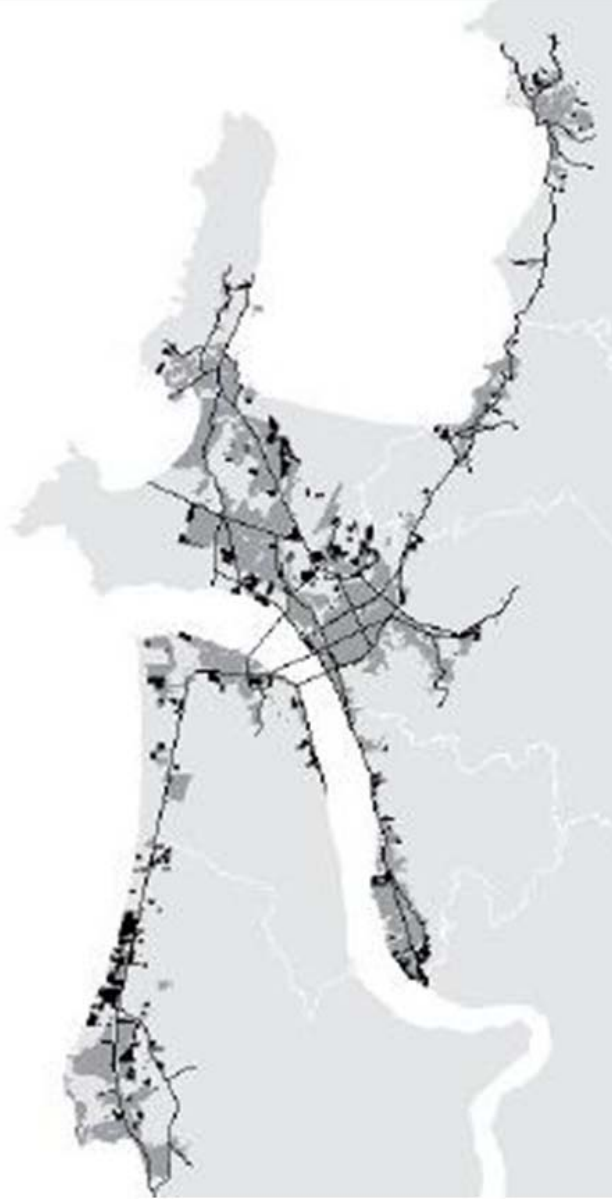

Fig 6: Crecimiento disperso en "salto de rana" en el AMC. Fuente: Pérez y Salinas 2010 


\section{URBANI SMO}

ISSN 0717-5051

http://revistas. uchile.cl/index.php/RU/index
Geografía del poder y diseño del espacio público periférico en el Gran Concepción Geography of power and the design of peripheral public spaces in the Greater Concepción area

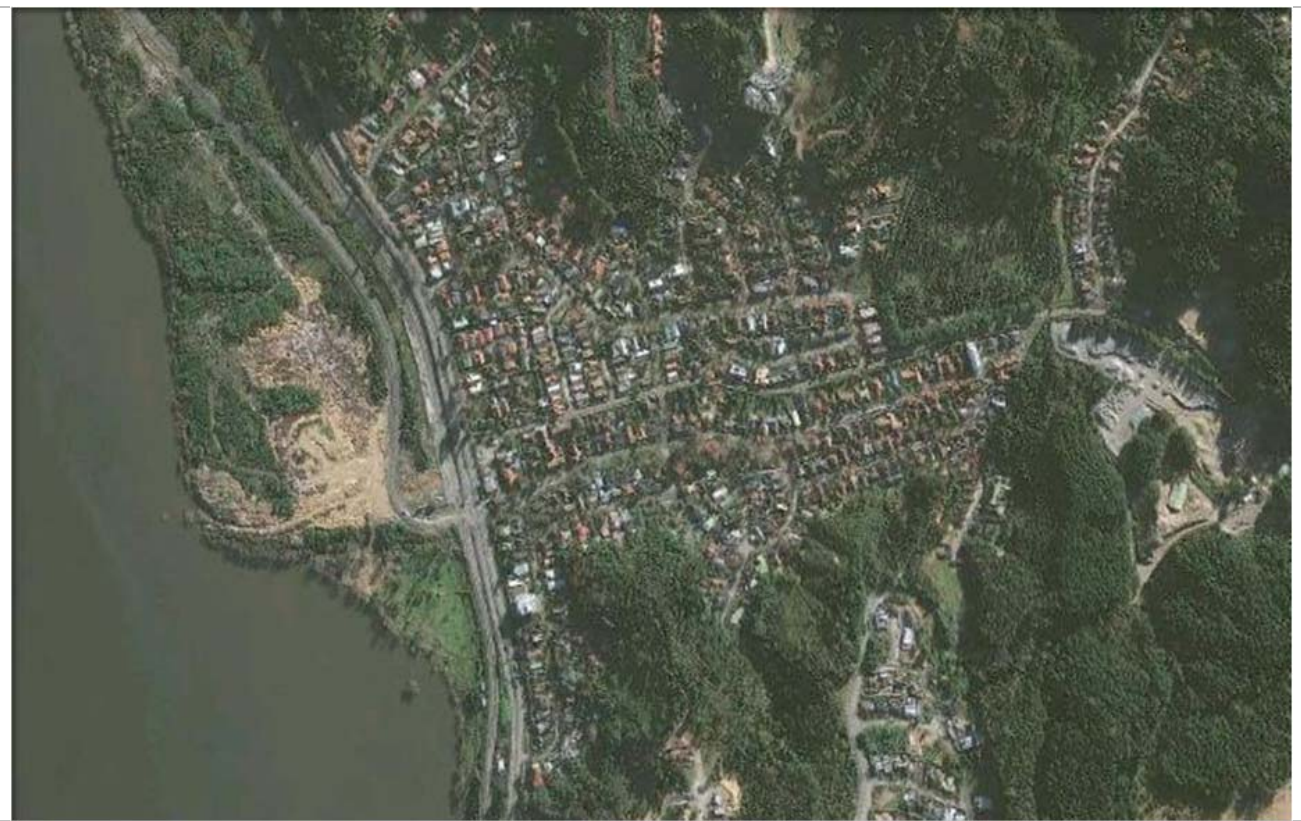

Fig 8: Tejido alveolar (Chiguayante). Fuente: Elaboración propia y Google Earth

Usualmente no existe conexión entre barrios contiguos y si existe, esta es solo parcial. La razón de ello es entre otras, que las geometrías de cada barrio suelen ser incompatibles, razón por la cual la continuidad de calles no es siempre posible. Por razones económicas, las calles y pasajes suelen tener predios a ambos lados, con lo cual es común que los cuerpos de agua limiten con fondos de sitio y no sean de libre acceso por espacios públicos (Fig 9). Esta situación es más usual en barrios más antiguos y cada vez menos recurrente en los barrios nuevos.

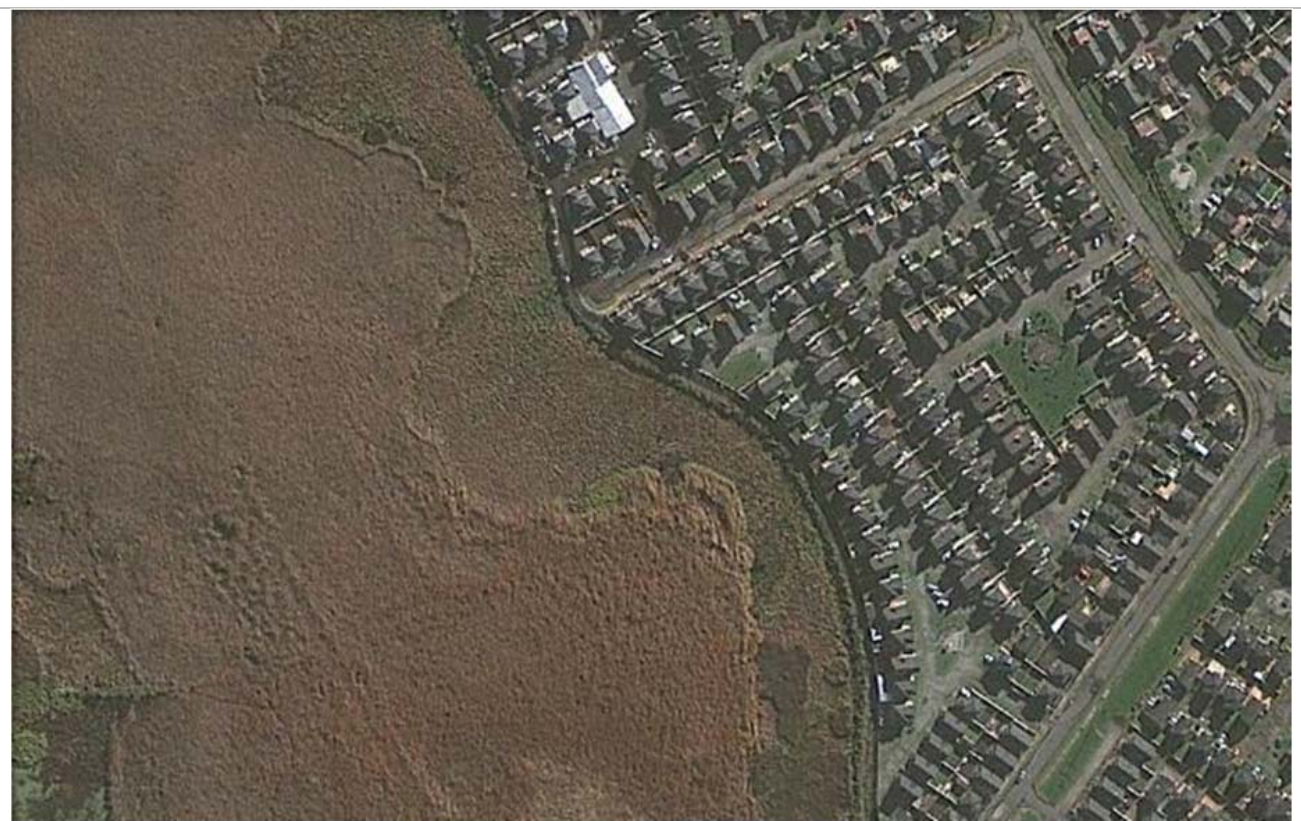

Fig 9: Vinculo de la trama urbana con los cuerpos de agua (San Pedro de la Paz). Fuente: Elaboración propia y Google Earth

77 
Se complementa con la red de calles, las áreas verdes públicas cedidas por los proyectos inmobiliarios según lo establecido en el artículo 70 de la ley urbana chilena (Ministerio de Vivienda y Urbanismo, 1975). Por lo general, las áreas verdes son espacios de tamaño menor pero variado, dispersos sin un criterio unificador común a toda la ciudad y a veces ubicadas en espacios residuales no usados por la comunidad. Su implementación suele básica o precaria en todos los niveles socioeconómicos y por lo general consiste en prado, bancas de madera y juegos infantiles que en muchos casos no tienen mayor durabilidad en el tiempo (Fig 10).

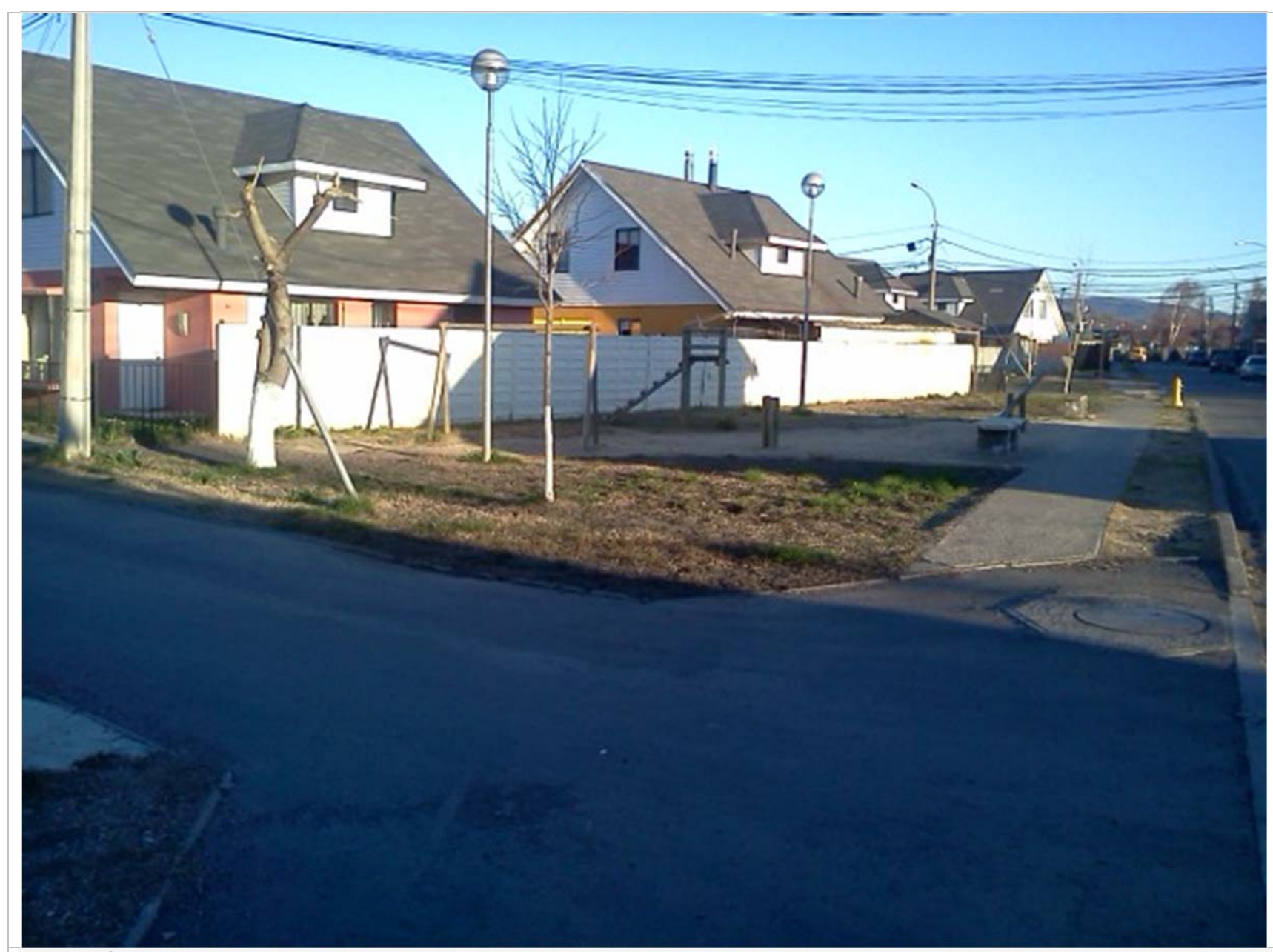

Fig 10: Áreas verdes precarias (Chiguayante). Fuente: Elaboración propia

Se indicaba anteriormente que es común que los cuerpos de agua no tengan libre acceso desde espacios públicos contiguos y lo mismo ocurre con aquellos de mayor tamaño como la Laguna Grande, Laguna Chica, Río Biobío, Río Andalién, Bahía de Talcahuano y Golfo de Arauco, etc. A parte las razones ya esgrimidas, hay otras causas. Por razones económicas, las urbanizaciones se van desarrollando a partir de las vías troncales y expresas lejanas de dichos cuerpos de agua y van eludiendo las menos favorables condiciones geográficas que suelen ofrecer los deslindes de los cuerpos de agua. Por último, en algunos casos las inmobiliarias buscan capitalizar estas ventajas paisajísticas para el uso exclusivo, con lo cual privan a la ciudad entera de estos espacios públicos. 


\section{REVISTA DE URBANI SMO}

ISSN 0717-5051

http://revistas. uchile.cl/index.php/RU/index
Geografía del poder y diseño del espacio público periférico en el

Gran Concepción

Geography of power and the design of peripheral public spaces in the Greater Concepción area

La primacía del mercado en el desarrollo urbano y la debilidad de los instrumentos de planificación, determina que las características de la demanda condicionen el diseño urbano. Cuando ello ocurre en un centro urbano, los efectos son más sutiles o imperceptibles porque hay un casco urbano consolidado, una densa red de espacios públicos y una mayor cantidad de intereses públicos y privados involucrada. Cuando ello ocurre en las periferias en proceso de consolidación, el impacto en la forma urbana, el espacio público y el paisaje es notorio. En materia residencial por ejemplo, la demanda de vivienda se caracteriza por la búsqueda de "productos" que ofrezcan "seguridad", lo cual se traduce en la proliferación de condominios cuyos espacios abiertos no son públicos sino comunes a sus residentes. Ello reduce la importancia relativa del espacio público en el tejido periférico, limitándose a las redes interurbanas sin un estándar de diseño que posibilite la estadía o su uso peatonal. (Fig 11)

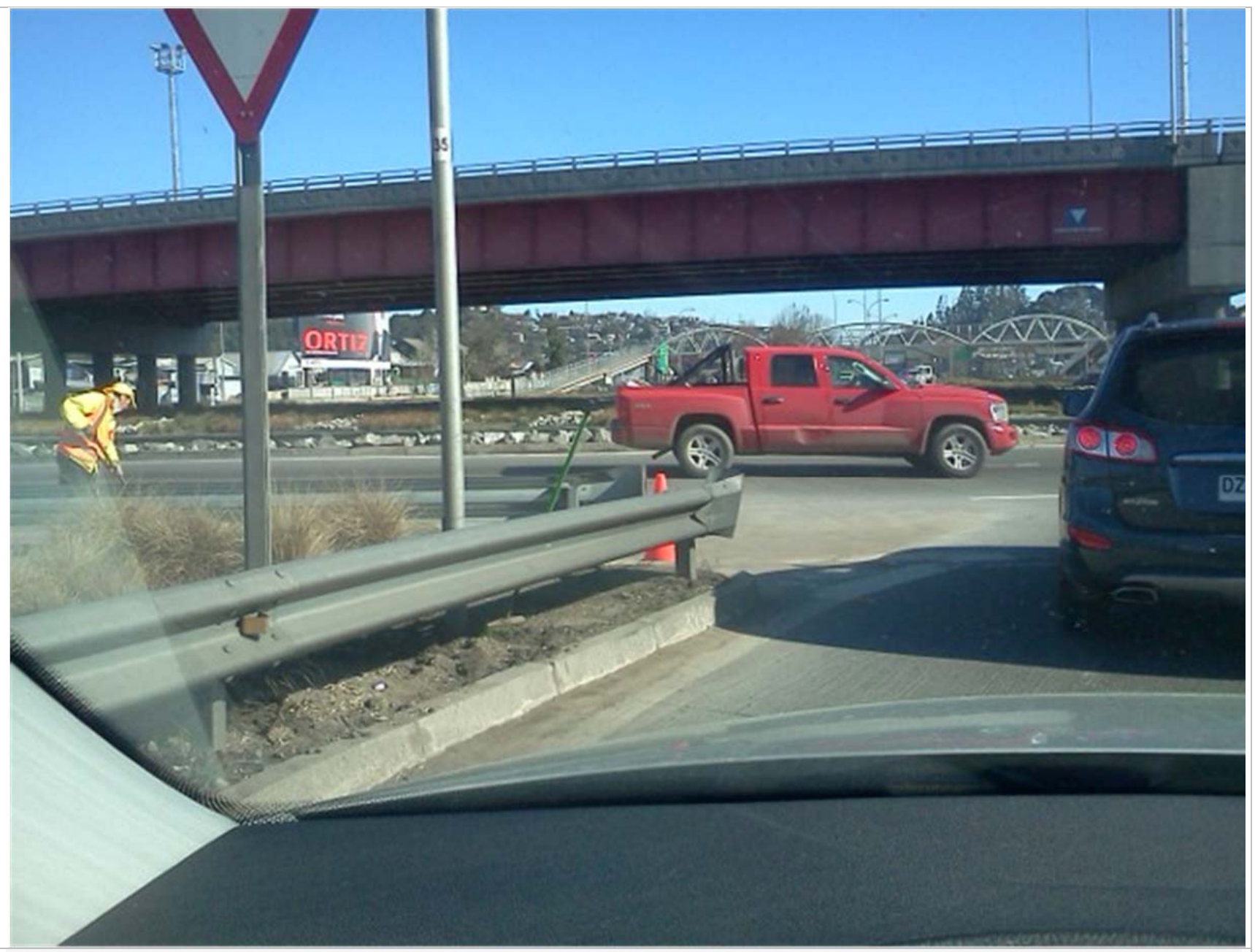

Fig 11: Espacio público interurbano (Concepción). Fuente: Elaboración propia 


\section{URBANI SMO}

ISSN 0717-5051

http://revistas.uchile.cl/index.php/RU/index
Geografía del poder y diseño del espacio público periférico en el Gran Concepción Geography of power and the design of peripheral public spaces in the Greater Concepción area

\section{Resultados.}

\section{Dificultades en la gestión de riesgos de desastres.}

Ante a la recurrente exposición de nuestras ciudades al riesgo de desastres, la disponibilidad de una red de espacios públicos redundante, continua y de alto estándar, es vital para asegurar la evacuación expedita de los habitantes, el apoyo por parte de los organismos encargados de la emergencia y el funcionamiento de la ciudad durante la fase de recuperación. Estas condiciones no se dan en las periferias urbanas del Gran Concepción, porque la red de espacios públicos es dependiente en extremo de unas pocas vías interurbanas sobre demandadas, porque la discontinuidad de dicha red hace más largos y tortuosos los recorridos y porque las zonas de seguridad son de dominio privado y no público. (Fig 12)

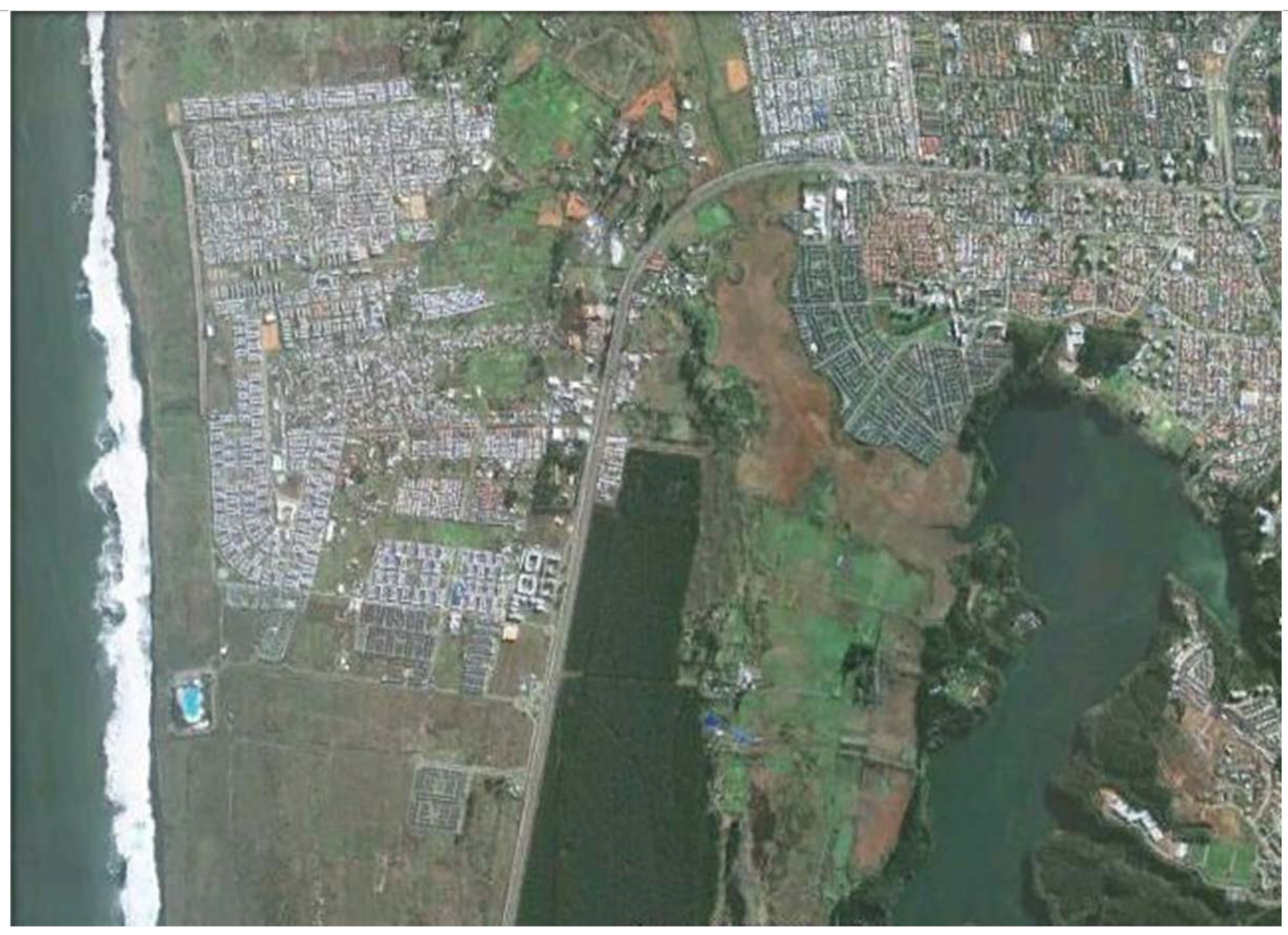

Fig 12: Exposición al riesgo natural, zonas vulnerables y zonas de seguridad (San Pedro de la Paz). Fuente: Elaboración propia y Google Earth

Más allá de los aspectos meramente espaciales, esta fragilidad tiene una expresión político institucional. En efecto, la dependencia que tiene la periferia pencopolitana de las vías interurbanas y áreas seguras no públicas, es en el fondo una dependencia de espacios cuya 


\section{URBANI SMO}

ISSN 0717-5051

http://revistas. uchile.cl/index.php/RU/index
Geografía del poder y diseño del espacio público periférico en el Gran Concepción

Geography of power and the design of peripheral public spaces in the Greater Concepción area

administración está en manos de organismos públicos desterritorializados o inversionistas privados, sin el sentido de emergencia o servicio público que entrega la experiencia local. Esta condición de vulnerabilidad político institucional ha sido descrita por los investigadores de La RED en diversas publicaciones hechas respecto de esta materia. (Maskrey, 1993)

Pero la vulnerabilidad no es el resultado solo de la precariedad de la red de espacios públicos. La vulnerabilidad se expresa con nitidez al analizar el grado de exposición que el tejido urbano periférico tiene a amenazas propias del contexto geográfico (remoción en masa, inundación, anegamiento y tsunami) (Romero \& Vidal, 2010) y de la diversidad de usos de suelo que coexisten en el área de estudio (industrias, actividad forestal) (Fig 13). Y es que históricamente las condiciones geomorfológicas del borde costero han favorecido la urbanización de las tierras bajas y la ocupación de las tierras altas por actividad forestal. Por otro lado, la vocación industrial del Área Metropolitana de Concepción ha determinado en el área de estudio, la coexistencia de actividades residenciales y productivas (Aliste \& Almendras, 2010). Más allá de un supuesto teórico, esta condición de vulnerabilidad quedó en evidencia durante y los días posteriores al terremoto de 2010 y como resultado de los incendios forestales de enero de 2012.

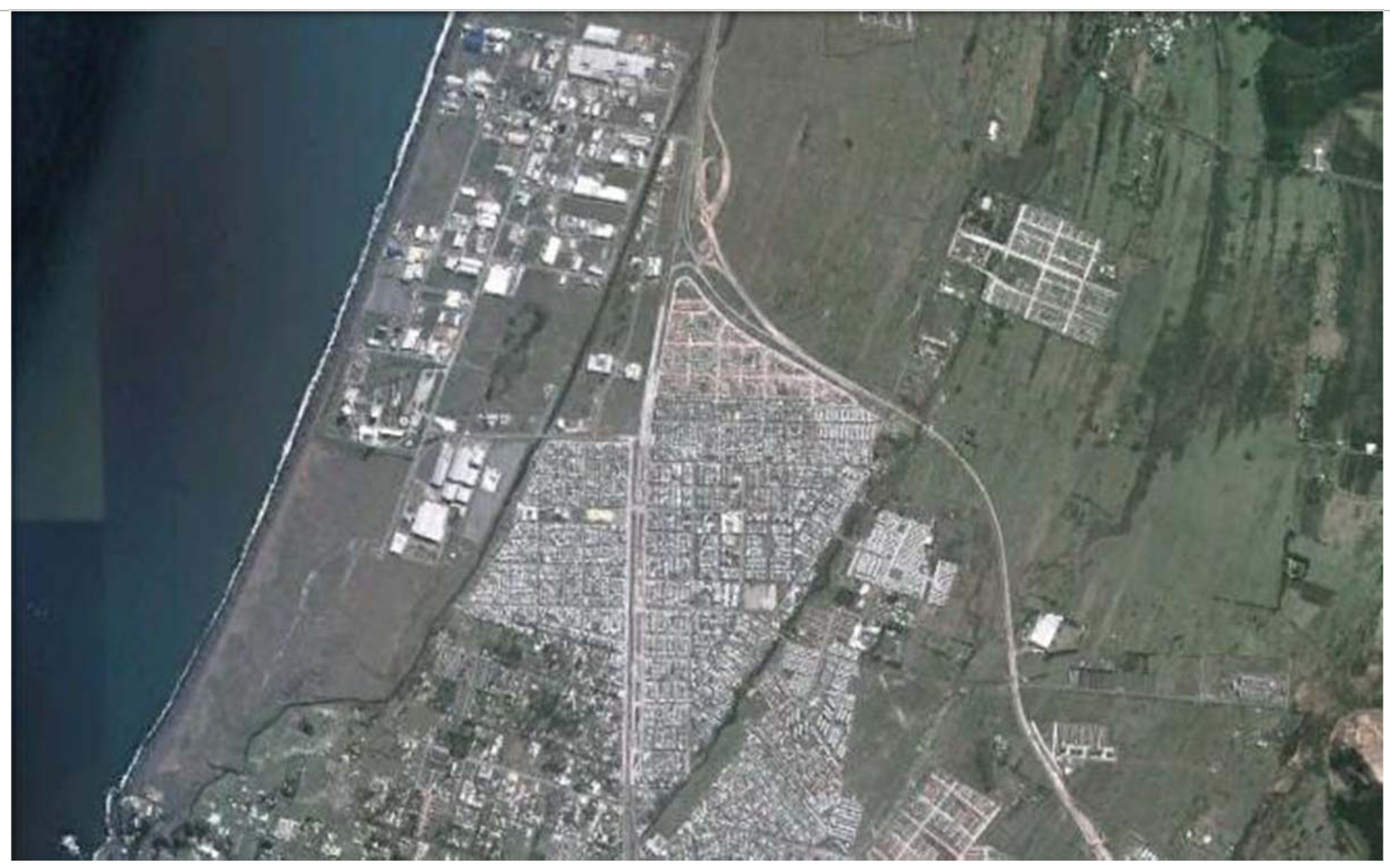

Fig 13: Riesgo natural y antrópico, zonas vulnerables y zonas de seguridad (Coronel). Fuente: Elaboración propia y Google Earth

\section{Dificultades de conectividad centro periferia.}

El desarrollo alveolar y disperso del espacio público periférico ocasiona varios efectos adicionales, como la sobre exigencia y congestión de unas pocas vías con los desplazamientos 
centro periferia (Gavilán \& Marmolejo, 2010), afectando estratégicamente la operación de la ciudad en su conjunto. Este monopolio de los desplazamientos centro periferia que tienen las vías interurbanas, se debe a la vocación industrial que determinó un diseño vial compatible con este objetivo (Aliste \& Almendras, 2010) y por otro a un contexto de gran carencia de inversión vial urbana por parte del Estado, en el mismo periodo en el cual justamente ha habido un mayor crecimiento urbano en el área de estudio (Gamez, 2001). Por otro lado el crecimiento en extensión en la periferia en donde los suelos son más rentables para el negocio inmobiliario, incrementa la demanda de acceso en torno a las vías interurbanas, produciendo focos de congestión en múltiples sectores a lo largo de esta, tornando más difícil resolver la congestión vial.

En efecto, estas vías interurbanas, tal y como fueron concebidas originalmente, no están concebidas para el "roce lateral" a las que son sometidas por el desarrollo residencial. Su adecuación requiere grandes inversiones que el Estado no está condicionado a hacer en los plazos que la demanda exige. Por otro lado, el sector privado evita hacer este tipo de inversiones, aduciendo su cuantía y las características del mercado local que no bastarían para financiar dichas obras. Este último argumento tiene algún asidero. En efecto el tamaño de los proyectos inmobiliarios son por lo general bastante reducidos en relación al volumen de aquellos que se desarrollan en la capital del país. En forma agregada, las iniciativas privadas si generan excedentes suficientes que permitiría invertir en espacio público de mejor estándar, pero requerirían formas de planificación y coordinación público privada que la institucionalidad urbana no prevé y que por tanto son difíciles de conducir por parte del municipio.

Por último ya hemos dicho que la morfología del espacio público periférico es ineficiente en términos de posibilitar desplazamientos cortos entre la residencia y los centros de servicio, lo cual es más elocuente en las áreas residenciales vulnerables que hacen uso de la locomoción colectiva (Gavilán \& Marmolejo, 2010). El carácter "orgánico" de la red de espacios públicos periféricos, obliga al transporte público a hacer extensos recorridos dentro de los barrios y lejos de los ejes interurbanos. Esto alarga los tiempos de desplazamiento, e incentiva el uso del vehículo particular. En otros términos, la morfología del espacio público periférico estimula el uso del vehículo particular, favorece la congestión vial urbana, lo cual afecta mayormente a los segmentos más vulnerables de la sociedad.

\section{Gobierno del espacio público periférico.}

Se mencionaba que el problema del gobierno del espacio público periférico tiene dos dimensiones a lo menos para ser analizada. Una que nos permite entender como el aparato público lo administra en forma más o menos eficiente y resuelve sus problemas (la gobernabilidad) y el otro que nos permite comprender la forma como la ciudadanía incide en las materias vinculadas a los problemas del espacio público, es decir la gobernancia.

Quedó en evidencia en los párrafos anteriores, que la gobernabilidad del espacio público en la periferia urbana es dificultosa en tanto concurren en ellas actores desterritorializados con objetivos institucionales disfuncionales con la realidad urbana como es el caso de la Dirección de Vialidad, el Departamento de Concesiones, Ferrocarriles del Estado y Gobernación Marítima. El menor peso relativo de la red de espacios públicos administrados por el municipio, versus las vías interurbanas y paños de dominio exclusivamente privado; redunda en menor capacidad de los poderes locales para resolver las demandas sobre el espacio público en el área de estudio.

De ello resulta un desequilibrio de poder en favor de los poderes públicos desterritorializados, grandes propietarios de suelo, inmobiliarias, grupos industriales y forestales, en desmedro del 
nivel local. Las limitadas capacidades presupuestarias de los municipios y su dependencia del presupuesto nacional, impide revertir estos desequilibrios sobre la base de crear grandes proyectos de espacio público y convertirse en "socios" relevantes en su gestión. En los hechos, las condiciones económicas y políticas condenan a los municipios a ejercer un rol de administradores de recursos externos y una atomizada malla de espacios públicos locales de bajo estándar.

Consecuencialmente, la gobernancia del espacio público o soberanía que tiene el ciudadano sobre este, es bastante limitada en tanto el mandato que entrega por medio de la elección popular a los municipios se ve truncado por el limitado ámbito de acción del poder local. Tampoco puede la ciudadanía ejercer poder sobre los otros actores urbanos, dados que estos no son elegidos por soberanía popular o porque la acción sobre el sector privado es incierta, dificultosa e ineficaz. Más allá del plano meramente teórico, este fenómeno se expresa en la desaprobación pública que son objeto tanto las autoridades como el empresariado en la medida que la ciudadanía percibe que los primeros no abordan ni menos resuelven las problemáticas que aquejan a los ciudadanos y los otros velan por sus intereses sectoriales afectando la calidad de vida en la ciudad sin mitigar dichos impactos.

Con todo, existe coherencia entre la percepción ciudadana y la hipótesis planteada al comienzo: Al momento de incidir en la calidad del espacio público, existe un desequilibrio de poder manifiesto entre las capacidades que tiene el poder público central y el sector privado por un lado y el poder local y los ciudadanos por otro. La clave está en las capacidades que ambos polos de poder tienen para diseñar y administrar el espacio público.

\section{Perspectivas para el diseño del espacio público periférico.}

La distribución del poder en las periferias pencopolitanas limitan las capacidades gobierno del espacio público pero también afectan la soberanía local en estas partes de la ciudad. Esta geografía social del poder urbano, determina la forma de actuar sobre el espacio público periférico y especialmente como el diseñador urbano opera sobre este. Sin pretender emitir un pronunciamiento taxativo respecto de esta materia, el trabajo define cuatro claros ámbitos de acción para el diseñador urbano:

\section{Espacios públicos de gestión privada:}

Como se indicaba anteriormente, su emplazamiento y diseño son de resorte del agente inmobiliario privado y su estándar suele ser básico con un emplazamiento residual respecto del conjunto del área loteada. Sin embargo, la experiencia señala que su diseño y la relación que guarde respecto del paisaje o el resto de la urbanización (conformación de centralidades locales, plazas de barrios, relación con cuerpos de agua, etc.), puede ser determinante en la promoción del "producto inmobiliario" en el mercado de la vivienda. El espacio público que resulta de este modelo de gestión, tienen casi en todos los casos vocación eminentemente vecinal, dado que no suelen tener las dimensiones necesarias para convertirse en hitos urbanos relevantes para la ciudad en su conjunto. (Fig 14, Fig 15) 


\section{REVISTA DE}

\section{URBANI SMO}

ISSN 0717-5051

http://revistas. uchile.cl/index.php/RU/index
Geografía del poder y diseño del espacio público periférico en el Gran Concepción Geography of power and the design of peripheral public spaces in the Greater Concepción area

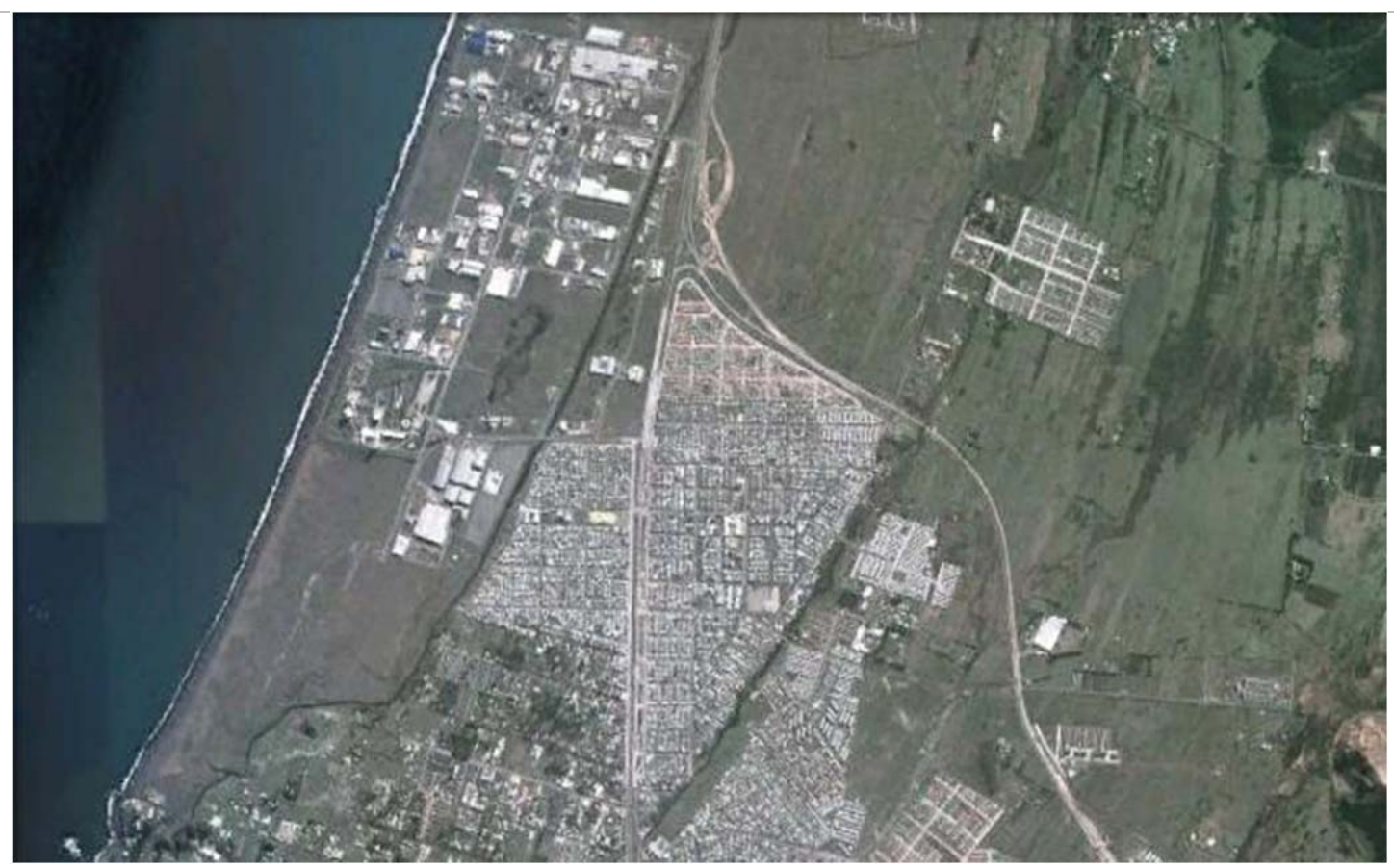

Fig 14: Espacios públicos de gestión privada (Talcahuano). Fuente: Elaboración propia

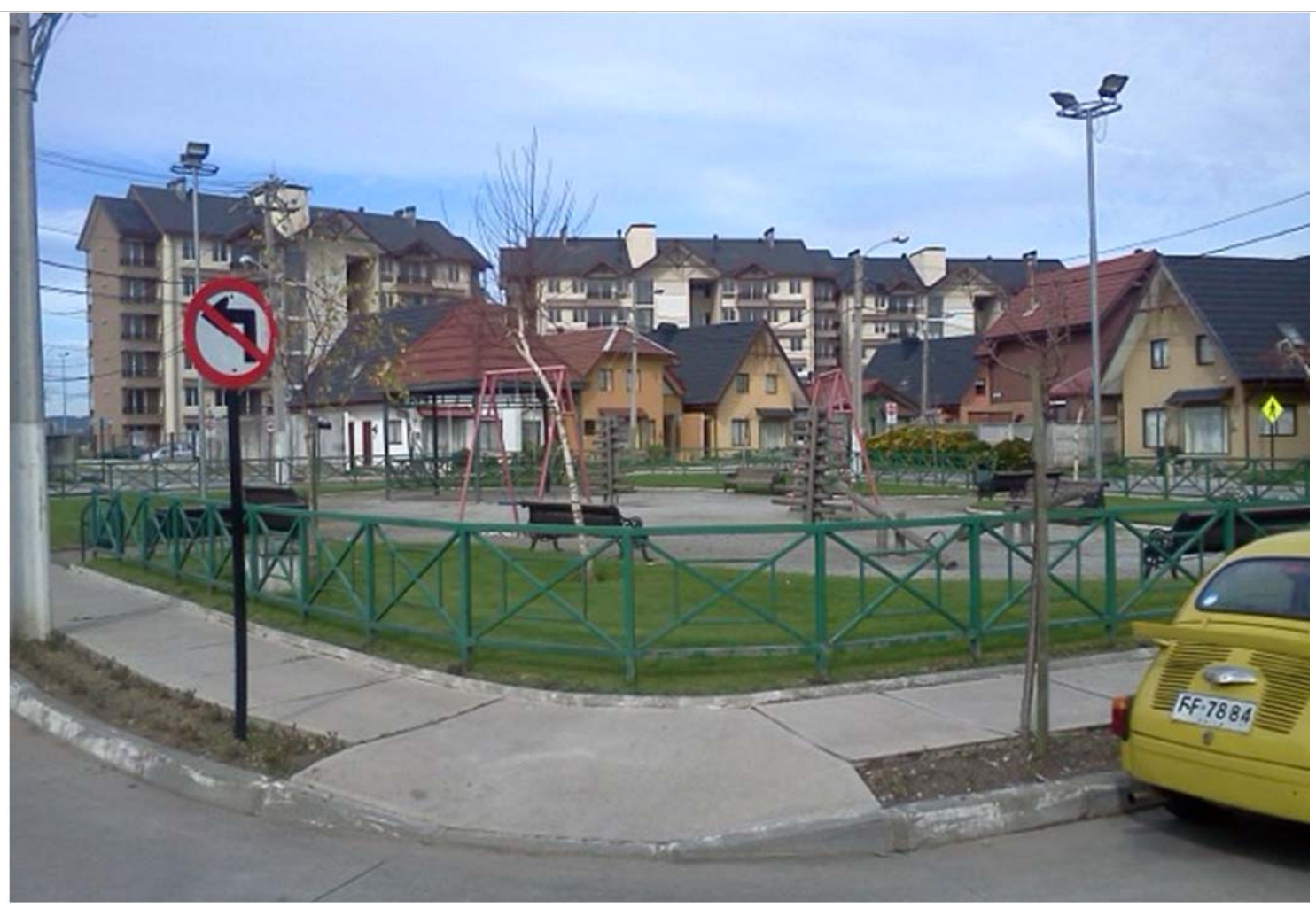

Fig 15: Espacios públicos de gestión privada (Talcahuano). Fuente: Elaboración propia 


\section{REVISTA DE \\ URBANI SMO}

ISSN 0717-5051

http://revistas.uchile.cl/index.php/RU/index
Geografía del poder y diseño del espacio público periférico en el Gran Concepción

Geography of power and the design of peripheral public spaces in the Greater Concepción area

\section{Espacios públicos "autogestionados".}

Tal y como se señalaba anteriormente, se materializan en los espacios públicos entregados por el urbanizador de acuerdo a las obligaciones establecidas en en artículo 70 de la ley urbana. Su ubicación y dimensiones son decididas por el sector privado en la fase de diseño del loteo y su implementación resulta de las iniciativas emprendidas por la comunidad, por lo general en alianza con los municipios, quienes financian directamente estas iniciativas o sirven de intermediarios para obtener fondos públicos para la ejecución. Los programas de Mejoramiento Urbano, de Recuperación de Barrios, FRIL, etc.; son algunos de estos fondos que usualmente han favorecido el desarrollo de este tipo de proyectos. Suelen ser de escala vecinal y contribuyen notablemente al fortalecimiento del capital social y el fomento de la identidad de barrio, ayudan en mayor o menor grado al mejoramiento de la calidad del espacio público pero no forzosamente a la integración del barrio con el resto de la ciudad. (Fig 16, Fig 17)

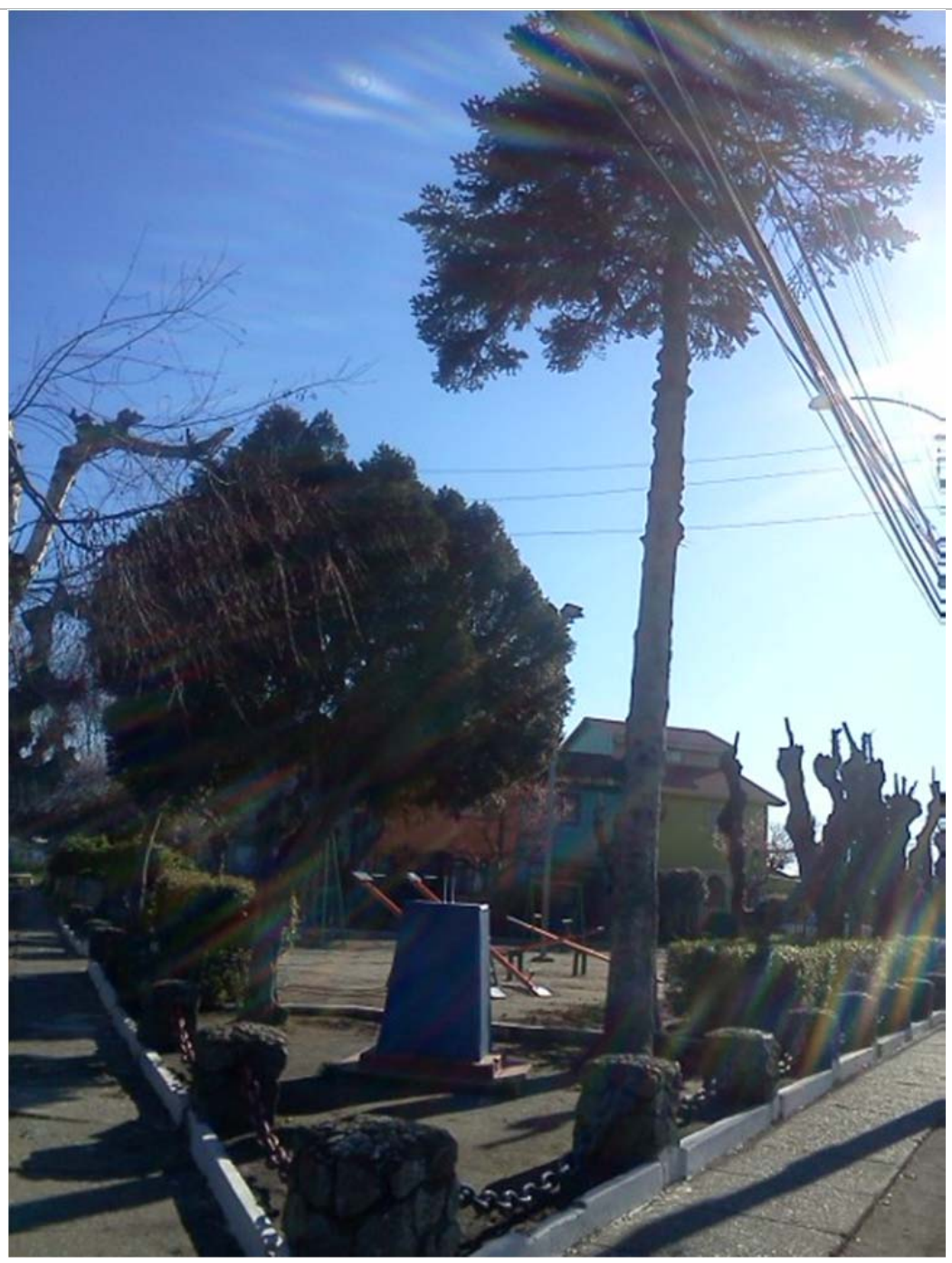

Fig 16: Espacios públicos autogestionados (Hualpén). Fuente: Elaboración propia 


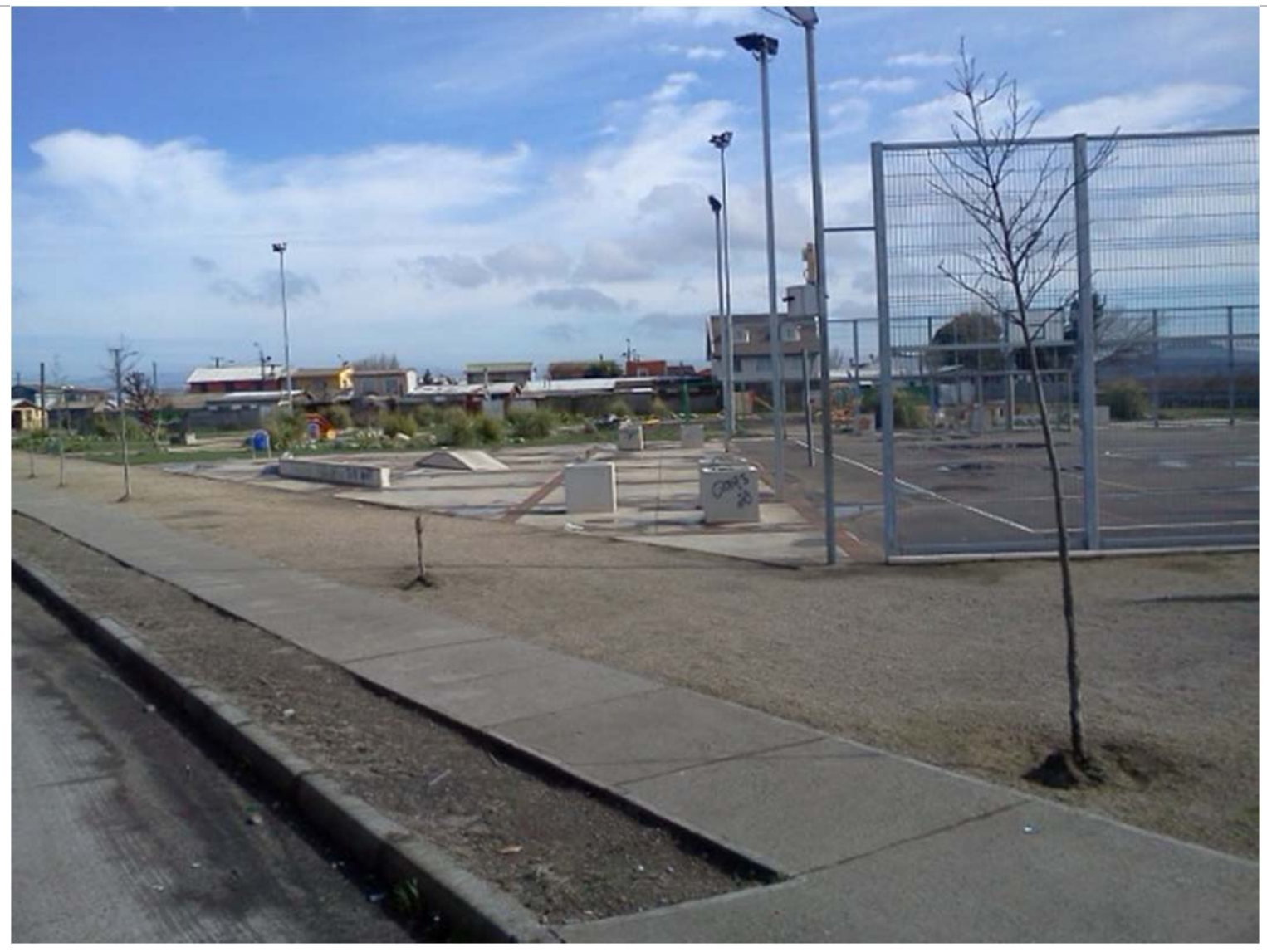

Fig 17: Espacios públicos autogestionados (San Pedro de la Paz). Fuente: Elaboración propia

\section{Espacios públicos de gestión pública multisectorial.}

El espacio público de escala urbana e interurbana, por sus dimensiones y la inversión que proporcionalmente requiere, necesitan grandes extensiones de terreno y recursos que los municipios de la periferia urbana pencopolitana usualmente no disponen en su propio patrimonio. Ello obliga que los poderes locales construyan alianzas con otros organismos del Estado a objeto de validar la pertinencia del proyecto, proveerse de los terrenos necesarios, se faciliten los recursos para expropiación y ejecución de la obra y algunas veces, la obtención de los permisos sectoriales necesarios para el financiamiento y operación de las obras.

Las complejidades de gestión que conlleva este tipo de asociaciones entre organismos del Estado, así como la gran cantidad de recursos que ello implica, determina que sean iniciativas escasas, muy lentas en su materialización, de destino incierto y a veces, como es el caso de los corredores de transporte público, sean lideradas por otros organismos públicos desterritorializados, no los poderes locales y mucho menos la comunidad. Ello mismo determina que los municipios pasan a ser meros colaboradores y no gestores de las iniciativas, participando en las mesas técnicas de revisión de los proyectos y haciendo gestiones políticas para su materialización. (Fig 18) 


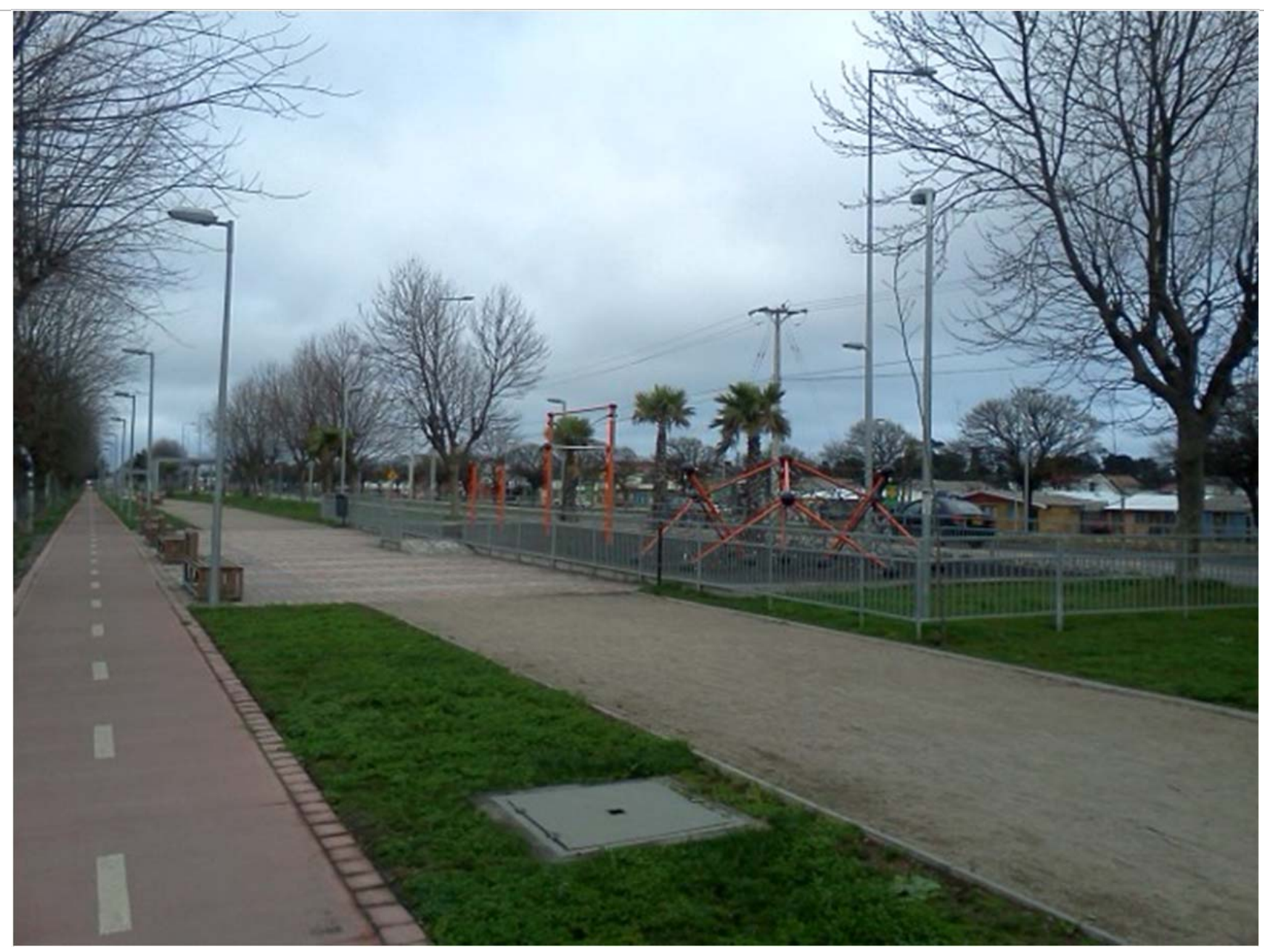

Fig 18: Espacios públicos de gestión pública multisectorial (Coronel). Fuente: Elaboración propia

\section{Espacios públicos de gestión público privada.}

Las dificultades para materializar espacios públicos de escala urbana, derivadas de las limitaciones económicas y políticas del poder local e incluso en algunos casos el Estado en su conjunto, determinó la elaboración de instrumentos legales de gestión público - privados como la Ley de Concesiones y la Ley de Financiamiento Urbano Compartido (Ministerio de Vivienda y Urbanismo, 2003). Estas herramientas permiten que el Estado y los municipios accedan a recursos privados para la ejecución de espacios públicos y palien sus deficiencias financieras, reduciendo con ello los tiempos de gestión.

Sin embargo, la Ley de Financiamiento Urbano Compartido lleva implícito mecanismos de contraprestaciones según los cuales el inversionista obtiene retorno de su inversión por medio de la transferencia de terrenos municipales o concesión de bienes públicos; condiciones que los municipios del área en estudio no siempre están en condiciones de cumplir. Las razones de este tipo de dificultades están dadas por el hecho que las administraciones locales no suelen tener terrenos de su propiedad económicamente convenientes para los inversores o porque la 87 


\section{REVISTA DE \\ URBANI SMO}

ISSN 0717-5051

http://revistas. uchile.cl/index.php/RU/index
Geografía del poder y diseño del espacio público periférico en el Gran Concepción Geography of power and the design of peripheral public spaces in the Greater Concepción area

concesión de espacios públicos es viable cuando estos espacios tienen una localización urbana suficientemente céntrica, como para que el sector privado pueda rentar de ellos. Por su propia condición periférica y los "vicios" de origen en el diseño de los espacios públicos, estas condiciones no se dan usualmente en la periferia urbana.

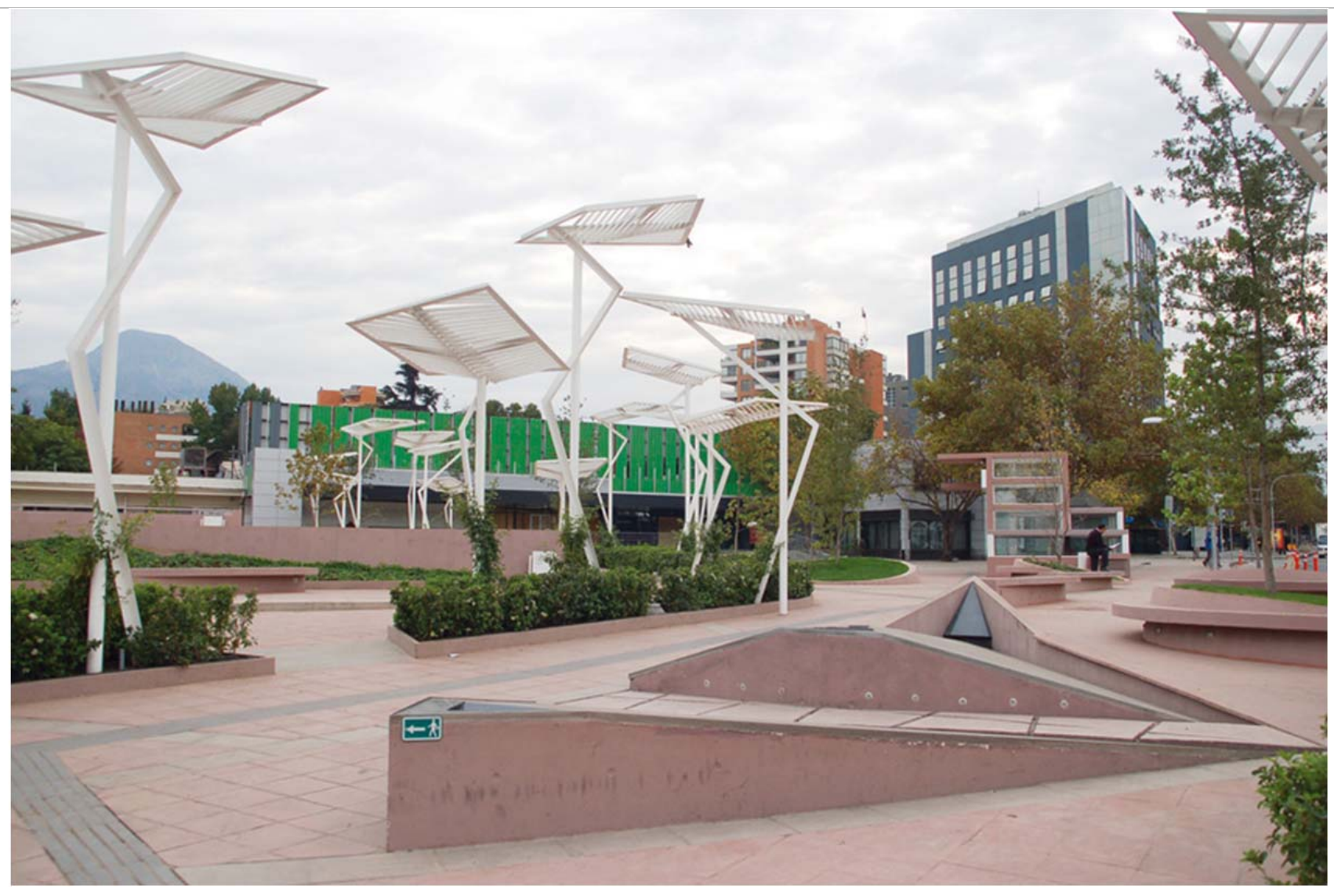

Fig 19: Espacios públicos de gestión público privada (Santiago de Chile). Fuente: Elaboración propia

\section{Reflexiones finales.}

La geografía del poder público y privado en las periferias urbanas del Área Metropolitana de Concepción determina una estructura del espacio público atomizada y precaria que vulnera las comunidades frente a los riesgos naturales y antrópicos, dificulta la conectividad y limita su gobierno por parte de los municipios y la ciudadanía. En lo especifico; la estructura de propiedad mayoritariamente privada, la legalidad urbana, la institucionalidad político administrativa y los déficits económico - patrimoniales de los municipios; reducen la capacidad de gestión de estos últimos, así como de las comunidades locales. En contrapartida, concentra la capacidad de tomar decisiones en aquellos que detienen el dominio del suelo periférico, la administración de los espacios públicos estructurantes y los recursos para la inversión.

En dicho contexto, la acción del diseñador urbano sobre el espacio público, se centra, en la práctica, en cuatro ámbitos: 
- El apoyo de la gestión privada en la escala vecinal con fines comerciales;

- El apoyo de la gestión municipal y las comunidades en proyectos de escala vecinal con fines comunitarios;

- El apoyo de la gestión pública intersectorial en proyectos de escala urbana e interurbana con fines urbanos.

- El apoyo de la gestión público privada de proyectos de escala urbana e interurbana con fines urbanos y comerciales.

De ello se deduce que las relaciones de poder público y privado en el área de estudio, determinan que las decisiones de diseño urbano sobre el espacio público están, en la práctica, fuera de la soberanía local representada por la comunidad y los municipios, colocando el centro de gravedad de la toma de decisiones en otros agentes extra urbanos con intereses no forzosamente alineados con las necesidades de la ciudad o de la pieza urbana en cuestión.

89 


\section{BI BLI OGRAFÍ A}

- Ahumada, J. (2009). Paradigmas de la admin sitración del Estado. Santiago de Chile: Academia de Humanismo Cristiano.

- Aliste, E., \& Almendras, A. (2010). Trayectoria territorial de la Conurbación Concepción Talcahuano: Industria, asentamientos humanos y expresión espacial del desarrollo, 1950 2000. En L. Perez, \& R. Hidalgo, Concepción Metropolitano: Evolución y desafíos (págs. 123149). Concepción: Universidad de Concepción.

- Arroyo, J. (2011). Espacio público. Entre afirmaciones y desplazamientos. Santa Fé, Argentina: Universidad del Litoral.

- Benevolo, L. (1982). La ciudad liberal y postliberal. En L. Benevolo, Diseño de la Ciudad - 5: El Arte y la ciudad contemporánea (págs. 23-47). Barcelona: Gustavo Gili.

- Coelho, M. P., \& Diniz, E. (1997). Gobernabilidad, gobierno local y pobreza en Brasil. En A. Rodríguez, \& L. Winchester, Ciudades y gobernabilidad en América Latina (págs. 99-152).

- De Mattos, C. A. (2002). Transformación de las ciudades latinoamericanas. ¿lmpactos de la globalización? EURE.

- Dror, Y. (1994). La capacidad de gobernar. Avance del informe del club de Roma. Cartagena de Indias: Circulo de Lectores.

- Gamez, V. (2001). Expresión urbana y territorial de la doctrina habitacional de la CORVI (1953 - 1976). En A. Raposo, Espacio urbano e ideología. El paradigma de la Corporación de Vivienda en la arquitectura habitacional chilena (págs. 201-247). Santiago de Chile: Universidad Central.

- Gavilán, U., \& Marmolejo, C. (2010). Estructura Urbana y movilidad cotidiana: Un analisis para el Area Metropolitana de Concepción. En L. Perez, \& R. Hidalgo, Concepción Metropolitano, Evolución y desafíos (págs. 189-214). Concepción: Universidad de Concepción.

- Hoffmann, A., \& Gysling, I. (2010). Desarrollo Histórico- Urbano de los centros poblados del Area Metropolitana de Concepción desde sus origenes a 1990. En L. Perez, \& R. Hidalgo, Concepción Metropolitano, evolución y desafíos (págs. 25-44). Concepción: Universidad de Concepción.

- Maskrey, A. (1993). Vulnerabilidad y mitigación de desastres. En A. MASKREY, Los desastres no son naturales. La Red.

- McCarney, P., Mohamed , A., \& Rodríguez, A. (1995). Towards an Understanding of Governance. En R. Stern, \&J. Bell, Urban Research in the Developing World (págs. 91-141).

- Ministerio de Hacienda. (1960). Decreto con fuerza de ley 340 sobre concesiones maritimas. Biblioteca Nacional.

- Ministerio de Obras Públicas. (1997). DFL N850 que fija texto refundido, coordinado y sistematizado de la Ley 15.840. Santiago de Chile: Biblioteca Nacional.

- Ministerio de Vivienda y Urbanismo. (1975). DFL 458, General de Urbanismo y Construcciones. Santiago de Chile, Chile: Biblioteca Nacional.

- Ministerio de Vivienda y Urbanismo. (1975). DL 1.305. Santiago de Chile: Biblioteca Nacional.

- Ministerio de Vivienda y Urbanismo. (1992). Ordenanza General de Urbanismo y Construcciones. Santiago de Chile: Biblioteca Nacional.

- Ministerio de Vivienda y Urbanismo. (2003). Ley 19865 sobre Financiamiento Urbano Compartido. Santiago de Chile: Biblioteca Nacional.

- Ministerio de Vivienda y Urbanismo. (2003). Plan Regulador Metropolitano de Concepción. Concepción.

- Ministerio del interior. (2002). Ley Nº Orgánica Constitucional de Municipalidades. Santiago de Chile: Biblioteca Nacional.

90 Departamento de Urbanismo - FAU - Universidad de Chile 
- Morris, A. (1979). Ciudades - Estado griegas. En A. Morris, Historia de la Forma Urbana desde sus origenes hasta la Revolución Industrial (pág. 43). Barcelona: Gustavo Gili.

- Perez, L., \& Salinas, E. (2006). Crecimiento urbano y globalización: Transformaciones del área metropolitana de Concepción, Chile, 1992 - 2002. Scripta Nova.

- Republica de Chile. (1980). Constitución Politica de la República.

- Romero, H., \& Vidal, C. (2010). La urbanización de las cuencas de los ríos Bio Bio y Andalién y sus efectos sobre los riesgos de inndación y anegamiento de la ciudad de Concepción. En L. Perez, \& R. Hidalgo, Concepción Metropolitano: Evolución y desfíos (págs. 285-300). Concepción: Universidad de Concepción.

- Salinas, E. (2010). Procesos urbanos recientes en el área metropolitana de Concepción. En L. Perez, \& R. Hidalgo, Concepción Metropolitano, Evolución y desafíos (págs. 230, 231). Concepción: Universidad de Concepción.

- Sassens, S. (2003). Espectros de la Globalización. Fondo de Cultura Economica.

- Wilson, R. H., \& Cramer, R. (1996). International Workshop on Local Governance.

91 